\title{
RECENT ACQUISITIONS BY THE COOPER UNION MUSEUM
}

A picture book in honor of Calvin S. Hathaway 



\section{RECENT ACQUISITIONS BY THE COOPER UNION MUSEUM}

A picture book in honor of Calvin S. Hatharray.

New York. 1964 


\section{Musenm and Library Staff}

ADMINISTRATIVE

11. Christian Rohlfing, Administrator, Curator of Exhibitions

Mary Borden Ilall, Secretary"

Nary A. Noon, Recorder

Mrs. Joln J. Blackwelder, Catalogue Supervisor

MIrs. C. John Mitchell, Receptionist

CURATORIAL

Hedy Backlin, Curator of Decorative Arts

Richard P. Nunder, Curator of Drawings and Prints

Alice Baldwin Beer, Curator of Textiles

Christa C. Nayer, Assistant Curator of Tertiles

Edward L. Kallop, Associate Curator of

Exhibitions

$\perp \perp$ B R A Y

Gerd Muehsam, Librarian

Edith Adams, Librarian

TECHNICAL

Carl North, Assistant, Department of Decorative Arts

Anme Oellschlager, Assistant, Department of Drawings and Prints

Andrew Gross, Artist and Mounter, Department of Drawings and Prints

Jane Stuart, Artist and Mounter, Department of Textiles

\section{MA I T ENANCE}

Adam Bonczkowski, Guard

Adolph Humiecki, Guard

Walter Kilar, Guard

Elizabeth Roberts, Mousekeper
Published by former nnembers of the Advisory Conncil and by the staff of The Cooper Union Museum.

Pliotography by George Cowdery, Ferdinand Boesch, IIelga Photo Stuctio, Inc.

Copyright (C) 1964 by The Cooper Union Museum Library of Congress Catalogue Card No. $64_{-25} 655$ Printed in the United States of America 
CALVIN SUTLIFF HATIIAWAY graduated from Princeton University in 193\%, and did graduate work at Ilarvard University and New York University. Shortly thereafter he was taken on the staff of the Pemusylvania Mluseum of Art (changed to the Philadelphia Mnseum of Art) as Secretary to the Director and Editor of the Museum's publications. Later, he was given charge of the Department of Decorative Arts and the "Colonial Chain" of historic houses in Fairmount Park.

In 1935 he came to the Museum for the Arts of Decoration of The Cooper Union for the Advancement of Science and Art, first as Assistant, then as Associate Curator, and finally, in 1946 , as Curator, a title changed in $195^{1}$ to that of Director. In 1947 he was appointed Professor of Decorative Arts. On the last day of December, 1963 , he resigned, just two months short of thirty-one years of service with the Cooper Union Musenm. I Ie now occupies the post of R. Wistar Harvey Curator of Decorative Arts of the Philadelphia Mluseum of Art.

With the advent of war, he enlisted as a Private in 194.2, and terminated his military service four years later with the rank of Captain. His commissioned service was spent largely in Military Government Service for the Division of Mlonuments, Fine Arts and Archives, in Bavaria and

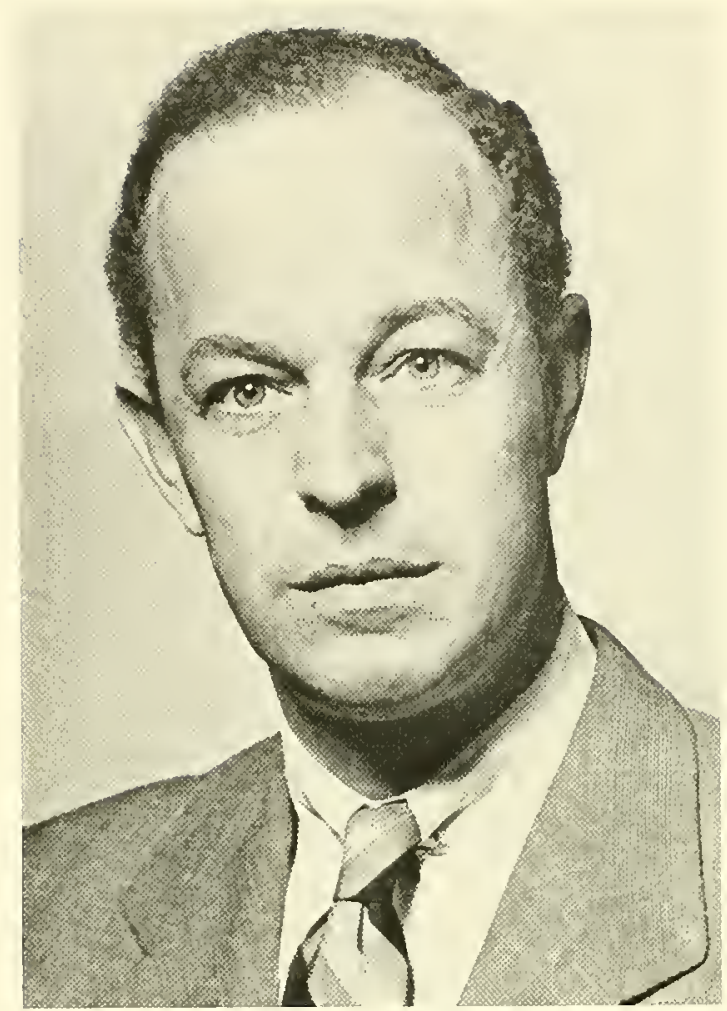

Austria, and later, in the Office of Military Govern ment for Germany, in Berlin. His decorations include the Military Order of the Loyal Legion and the Delaware Medal (Sweden).

In 1935 he was awarded a travelling fellowship by The American-Scandinavian Foundation. Professional affiliations held by him include membership in the American Association of Museunus, Association of American Museum Directors (one term as Vice-President), the International Institute for the Conservation of Museum Objects, the Artist-Craftsmen of New York (Board of Governors 
and Second Vice-President), Inter-Society Color Conncil, Anerican Institute of Interior Designers, Residence Lighting Forum, New Iork Section (Executive Board), Centre International d'Études des Textiles Anciens (American Correspondent and Vice-President), and the Fine Arts Committee of the White IIouse. I Ie was also a menuber of the Nuseums Council of New Tork, and upon leaving New York was elected to honorary membership.

Mr. Hathaway's contributions to the development of the Cooper Union Mluseun are numerous and varied. Anong his initial undertakings was the organizing of a catalogue system for all objects received by the Nusenm from its beginning in 1 897. This included the establishing of accession numbers, the outline of classification of the objects, the designing of the various forms needed for daily operation, and the card catalogue which to this day offers the unique service of a comprehensive file available for public consultation. During World War II the Office of Military Govermment in Germany used this outline of classification as the basis for indexing looted works of art recovered by the United States military authorities in Germany. A number of museums and libraries in America have since studied and adopted this system.

In order to stimulate a broader interest in the Museum, Mr. Iathaway organized the Friends of the Museum program through which contributions were received for the purchase and repair of works of art, for publications, receptions and general physical improvement of the Museum. For the
Anumal Spring Gathering of the Friends of the Inseum, well-known speakers were engaged and exhibitions organized, factors which did much toward increasing the nembership of the Friends and extending an interest in the Museum beyond the neighborhood of Cooper Square.

In 1955 he initiated the Chronicle, an anmual scholarly publication devoted to objects or various units of the collections, which soon gained an international reputation in the field of the decorative arts. Articles which he personally contributed to the Chronicle inchule one devoted to French silversmithing of the 18 th century, others to the collection of drawings and watercolors by Tinslow Homer (the first article ever to be devoted to Homer's graphic art and a milestone in the study of this artist), the wallpaper collection, the drawings collection, a study of the Museum's development from 1897 to 1957 , and, in collaboration with Miss Jean E. Nailey, a detailed analysis of a group of rare early Chinese textiles, attributed to the third century B.C., the late Eastern Chou period. In order to present more fully certain collections, he instituted picture books devoted to the wallpaper collection and to that of printed textiles. As a part of the Museum's Sixtieth Anniversary celebration, an Illustratcd Survey of the Collections was published, the design of which was the model for this present publication.

Seeing the need for a program of changing exhibitions, in $195^{8}$ lie arranged that gallery space be made available for such purposes. Under Nr. Hathaway's imaginative direction, such varied ex- 
hibitions have taken place as French Silver from the Reign of Louis XII' to the Empire, Baked Clay. in the Service of Man, Four Thousand and One liuttons, With Hammer and Tongs, 2500 F., Nine Lires: The Cat in drt, All That Glisters, Leather in the Decorative Arts, Alter Ego (Masks), Lacquer, Conspicuous IT aist: IVaistcoats and Their Design, The Prince Regent's Style, Enamel, Ninetenth Century Jeuelry, Design by the Fard (Printed textiles), Ceramics by Picasso, Plane Geometry and Fancy Figures: The Art of Paper Folding, The Logic and Magic of Color, to name but some of these exhibitions, all of which were accompanied by printed and illustrated catalogues. Concerned with the necessity for a program of changing exhibitions, Mr. Hathaway stated: "While the collections form the comerstone of every museum, it is only by the use made of the collections that the success of a museum may be ganged... The most conspicuons derelopment has taken place in the program of temporary exlibitions . . based in large part on material in the Musemm's possession, reënforced with loans from generous collectors, musemms, and the designers and producers of our own day." Under his guidance participation by the Museum in trade and craft shows, home-furnishing and flower shows, as well as in loans to other museums and travelling exhibitions has resulted in an increased public awareness of the $\mathrm{Y}$ Iuseum's collections and services.

Until 1940, when the administration of the Musem library was transferred to that of the Cooper Union's Main Library, Mr. JTathaway daily scrutinized European and American dealers' catalogues for books needed for research in the decorative arts. Today, this library is outstanding of its kind on this side of the Atlantic.

Mr. I Jathaway's most recent contribution to the betterment of the Museum's physical arrangement and interpretation of its collections was the reinstallation of two suites of galleries, one devoted to The Elements of Design, the other to The Sources of Design, the latter completerl in the Spring of $19^{6} 3$. The raison d'être of these particular displays is that "besides maintaining collections representative of the good designs of today, yesterday, and the day before . . . a teaching and working organism such as the Cooper Union Museum should develop displays illustrative of the elements of design-form, color, texture, spatial relationships, illumination. The concepts, sometimes difficult to convey even experimentally in classroom and laboratory, still seem imperfectly understood by designers and producers of much that is offered in today's market. They are all aspects of that elusive ideal, quality, recognition of which is often described under the indefinable term, taste."

Ilis loyalty and deep sense of his responsibilities, and his patience in bringing to completion any task before him were the qualities which Calvin Hatharway imparted as example to his professional staff. To him the staff, individually and collectively, owes gratitude for the knowledge he shared and the guidance he provided in the conduct of the Museum during the nearly thirty-one years of his leadership. 

The most ancient silks in the Museun's collection, and the rarest, are a bomnet, a pair of mitts and fragments of a kerchief, discovered in a lacquer box excavated at Ch'ang-sha, in the Chinese province of Juman, and tentatively attributed to the third century, B.c., late Eastern Chou period. Though stained and dimmed after some two thousand years, they remain important examples of the extraordinary skill of Chinese silk weaving and mastery of design. The kerchief fragnuents are in a plain, or tabby weave, umpatterned, and now a deep crean color. The bonnet and mitts are in very fine warp-face weave in brown, remilion, honey color and yellow. In three patterns (two in the bounet and mitt finger ends are very similar) they present arrangements of subtle, geometric desigus, probably symbolic and certainly evidence of ancient culture. In Volume 2, number 10 of the Museum's Chronicle a study of these textiles was published by Jean E. Mailey and Calvin S. IJathaway, a collaboration resulting in a valuable scholarly contribution to our kuowledge of early Chinese textiles. A.B.B.
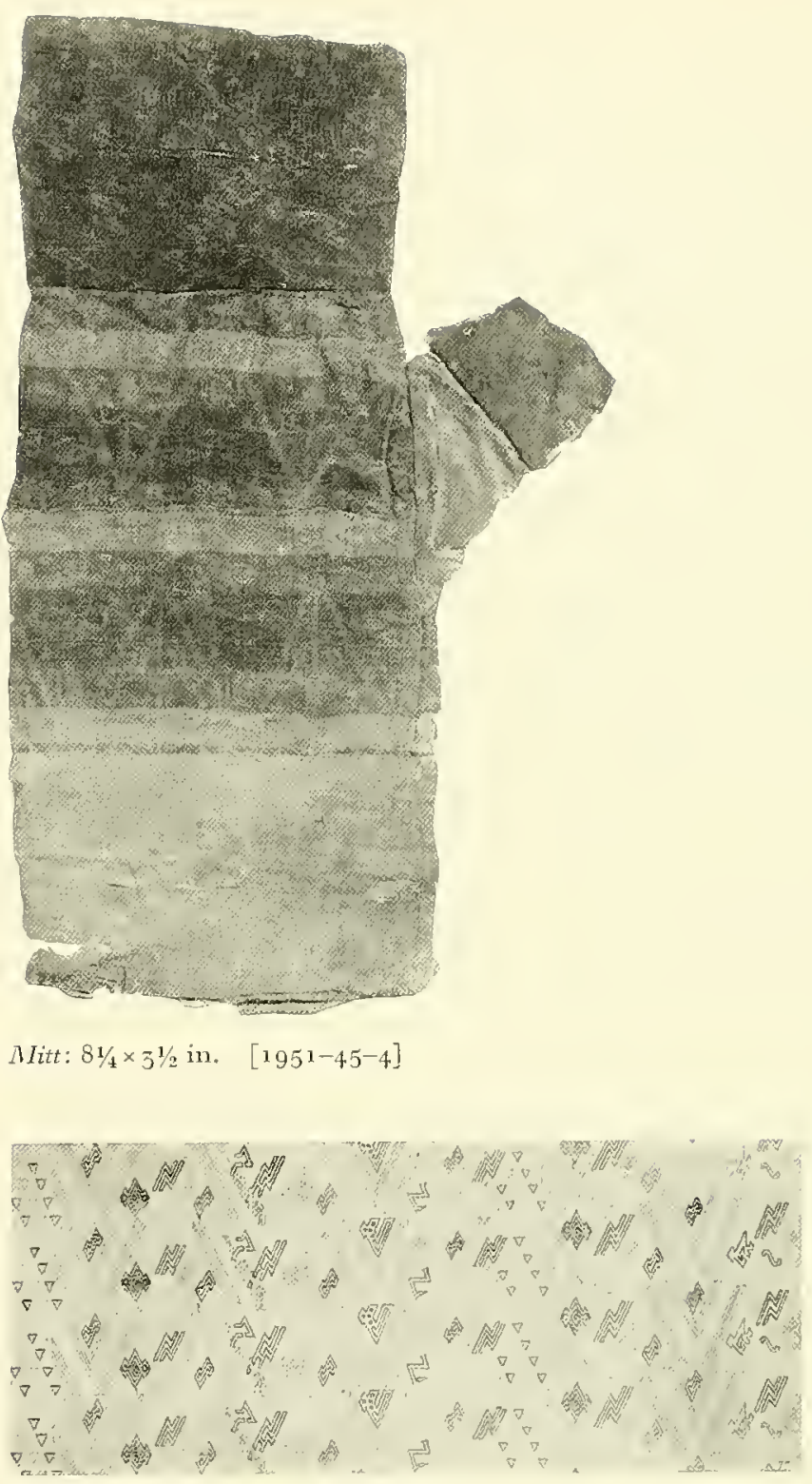

Diagram of pattern (detail) for-bornet 


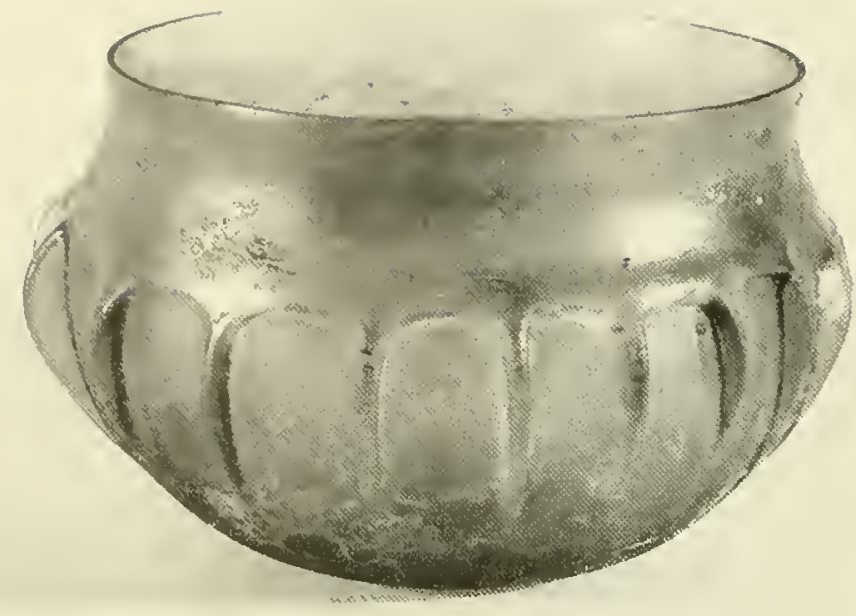

Diancter, $4 \frac{5}{5}$ in. $\quad\left[19^{6} 1-88-9\right]$

One of the earliest results of Man's attempts to create materials with properties different from those inherent in nature was the invention of glass. With its many possibilities of color, technique and use glassmaking never ceased to intrigue craftsmen and artists as its teclnology spread from Mesopotamia toward Egypt and the West. The Middle East remained for a long time the centre of the art, and it is from that area, probably from sidon, that this little bowl originates. It is a rariation on a well-known family of lotus-shaped bowls, some of which have rounded relief petals, others only their indication in raised flanges. Pale green in color, it is but one of many fine examples of ancient glass given the Museun by Mrs. Leo Wallerstein.

H.B. 
The art of the Chinese potter reached a remarkable peak during the 'T'ang Dynasty, that highly artistic and refined period corresponding approxi-

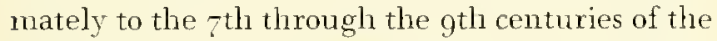
Christian era. Native experience in the craft was stimulated to new efforts by external cultural influences, mainly from Persia, with renote echoes from the earlier Hellenistic kingdons. In this stoneware amphora with a finely-crackled glaze, the decorative dragon handles of Micldle-Eastern origin en hance a classically crisp outline.

H.B.

Height, $15^{-3 / 4}$ in. $\quad\left[195^{8-94^{-1}}\right]$

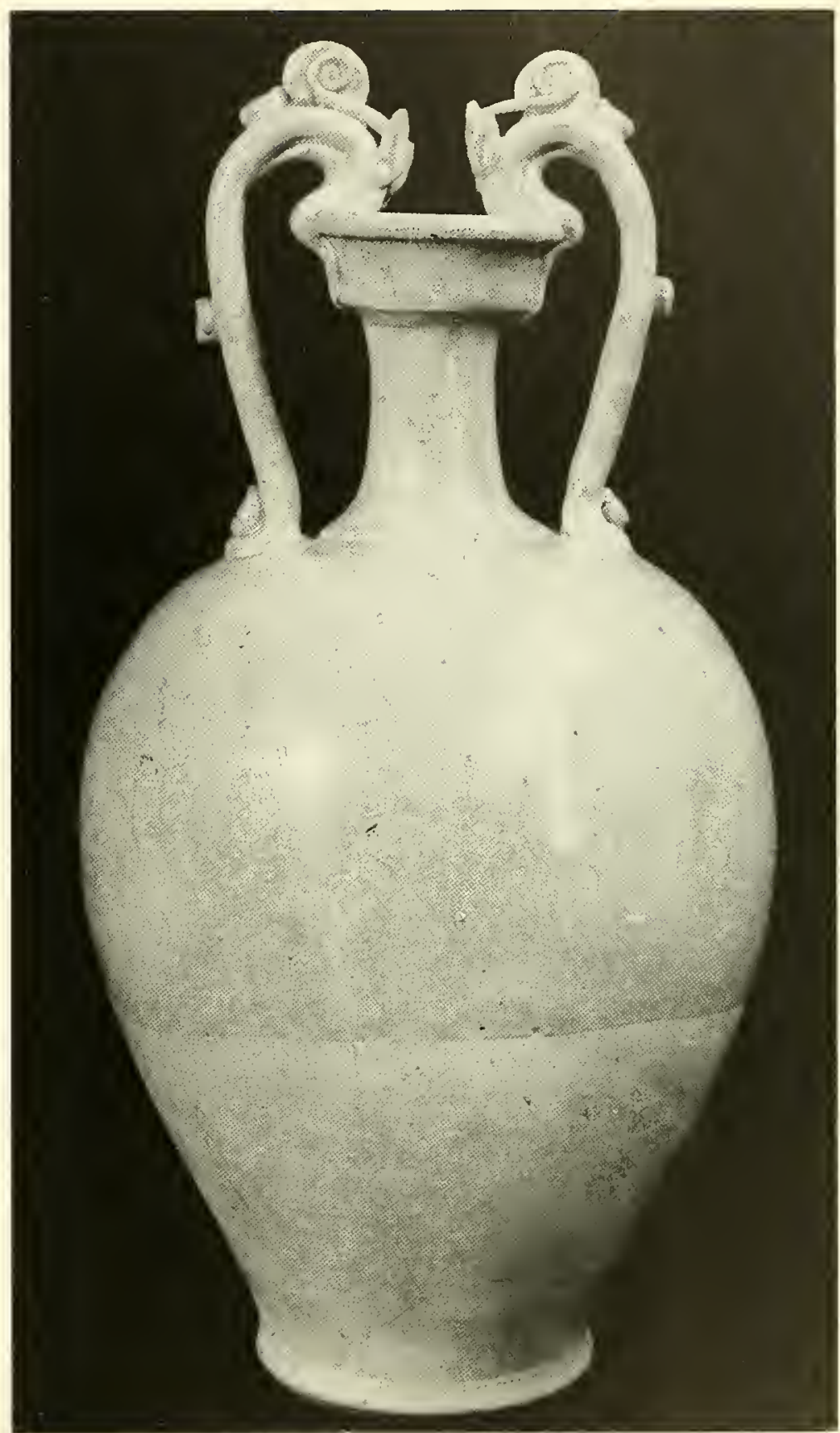




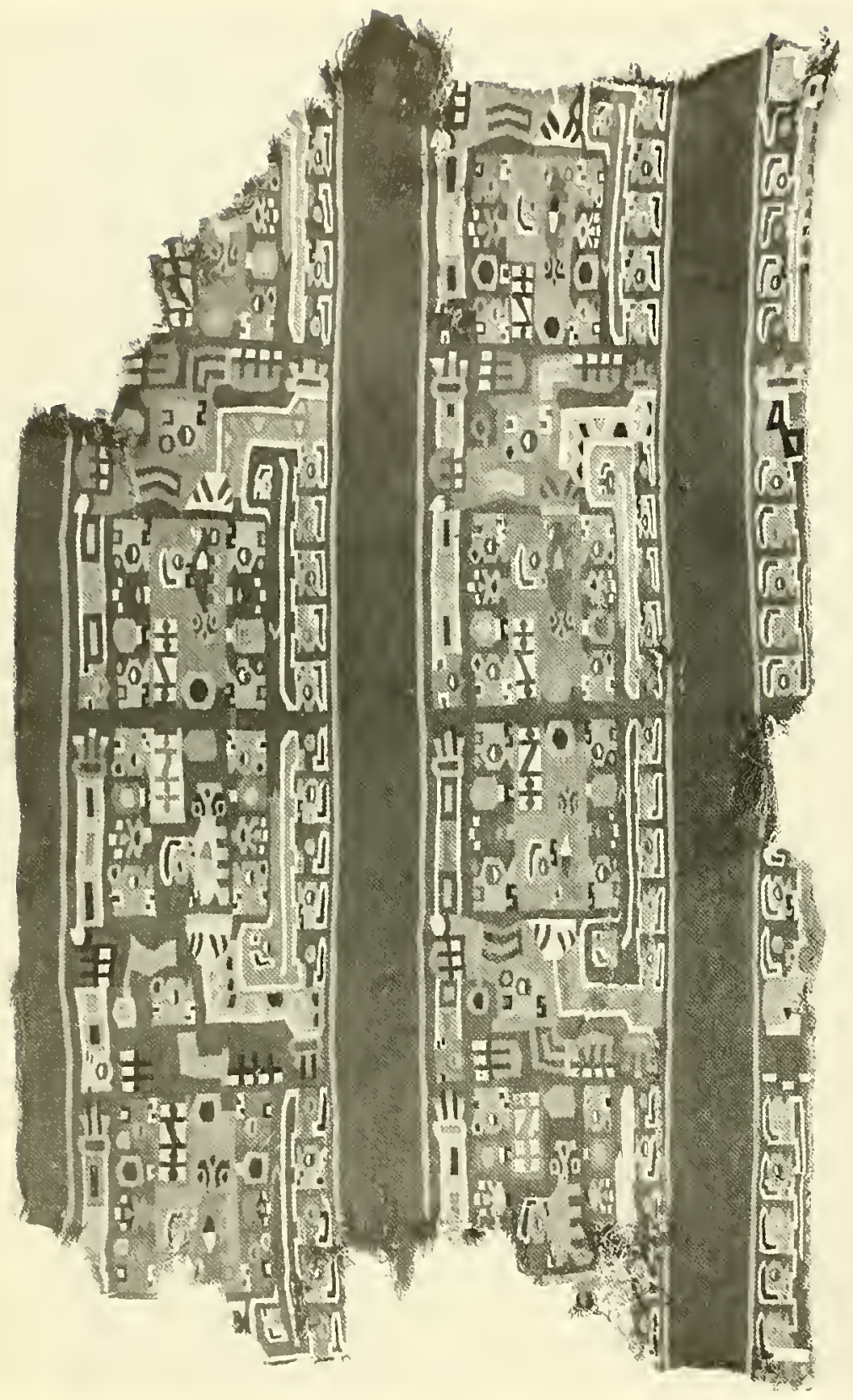

In the construction of a portion of a shirt from the pre-Columbian Tiahuanaco Culture of about 8 oo1000 A.D. is found a combination of alpaca wool wefts and cotton warps. The pattern is contained within wide, vertically-rumning bands, separated one from the other by a narrow stripe of brilliant red. The individual design unit shows a kneeling winged figure carrying a staff. In each instance it is introduced into the vertical bands in a fascinating juxtaposition with repeating design elements. Sometimes the motifs are reversed, sometimes color is reversed, at other times both alternations occur. The result is a design of extreme sophistication and refinement. c.c. M.

$5+1 / 4 \times 2018$ in. $\quad[1962-1-1]$ 
Two strands of delicate cast gold beacls, from the province of Coclé, Panana, the gift of Mrs. John Minslow, are examples of a pre-Columbian culture which existed from 500 to $15 t^{\circ} \mathrm{A}$.D., and produced not only a wide range of brilliant polychrome pottery but also a variety of ormaments in which hammered or cast gold was an important element. The recklaces were probably marle about 800 A.D. by a skillful process of casting, now lost. The little gold pendant, in the form of an eagle, combines the two techniques of casting and hammering; it is from Costa Rica and dates from the 12 th century. These ancient omanents are proof of crafts far from primitive, and suggest, as well, that instinctive appeal to the sense of touch, the enjoyment of which is satisfied only by ruming through one's fingers such fine works of gold. A.B.B.

$$
\begin{array}{r}
\text { Upper }(-1): 22 \mathrm{in.}(\text { length) }[1960-120-1,-2] \\
\text { Lower }(-2): 221 / 2 \mathrm{in.}(\text { length) } \\
\text { Pendant: } 7 / 8 \text { in. (length) } \quad[1960-28-1]
\end{array}
$$

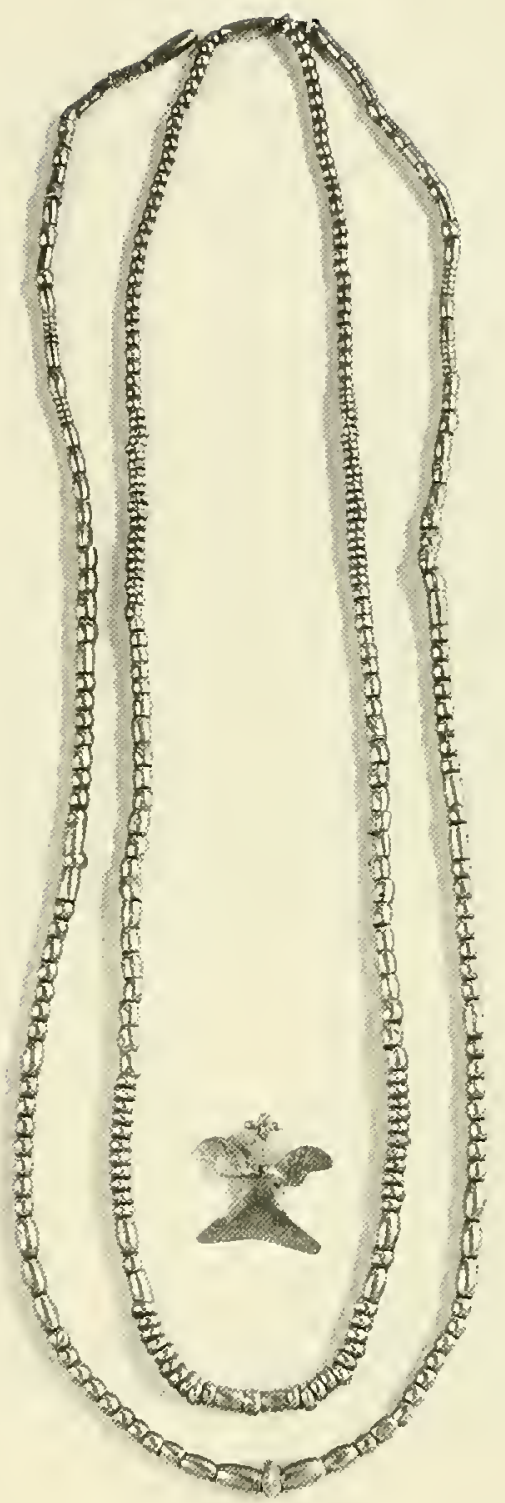




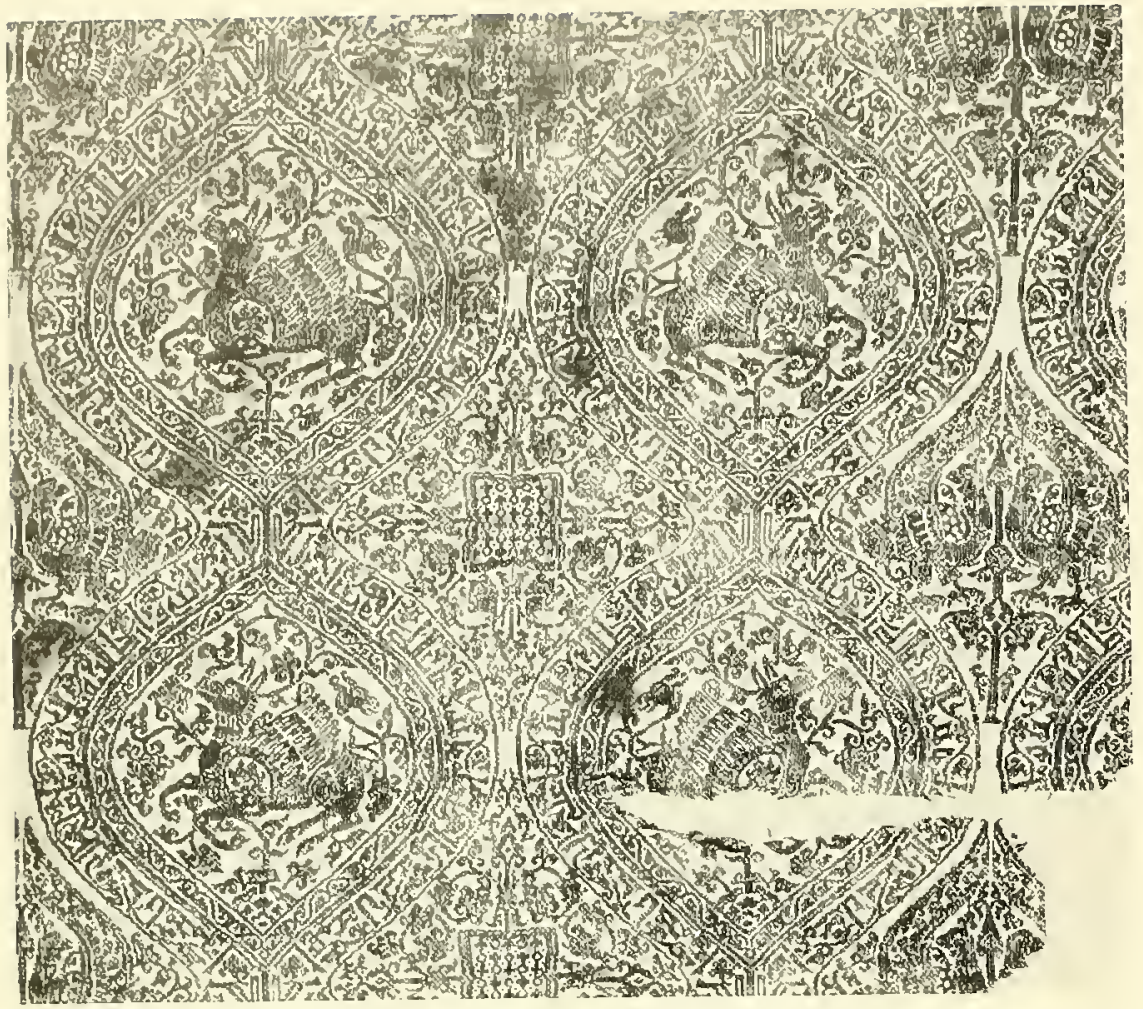

$15 \times 8$ in. (detail shown) $\left[19^{6} 1-96-1\right]$
The acquisition, through the Friends of the Museum Fund, of this silk adds to the Museun's collection of early textiles an example from that rare i 1th-century group of Persian silks of the Buyid Dynasty. To a muted color scheme of brown and cream a liveliness is added by the clever stippling effect produced by the warp twill weave. The vigor of pattern, complex but controlled, beguiles the eye. Though many of the design elements are familiar in Near-Eastern art, comparison with other known Buyid silks sets off this fragment as something of a departure in style. Less hieratic, less heraldic, the whole pattern is arranged against a background of agile floral ornament which presages the later, fuller development of MTohammedan design. Within the double frame of the ogival net move rinceaux against which runs a Kufic inscription: "Every son of woman, no matter how long he lives in security, is one day borne away on a stretcher," gloony testimony that this lovely textile was designed for use in burial. A.B.B. 
As Chinese porcelains spread through Asia toward the VTest, their fame elicited admiration and envy in collectors and spurred potters to attempt to capture their desirable qualities. One of the most successful initations which resulted in a whole new family of ceramic products, eventually known as majolica and faicnce, was created in the Mliddle East and carried from there to Moorish Spain, to Italy, and eventually across the Alps to Northerm Europe. This ceramic type is distinguished by an opaque white glaze, a light clay body, and by highfire colors of iron red, cobalt blue, copper green and black. These brilliant colors enbance the forceful design of this handsome flagon from Turkish Iznik, of about 1550 . Given to the Minseum by R. Thornton Wilson, it was formerly in the collection of Enrico Caruso and TVilliam Randolph Hearst. H. B.

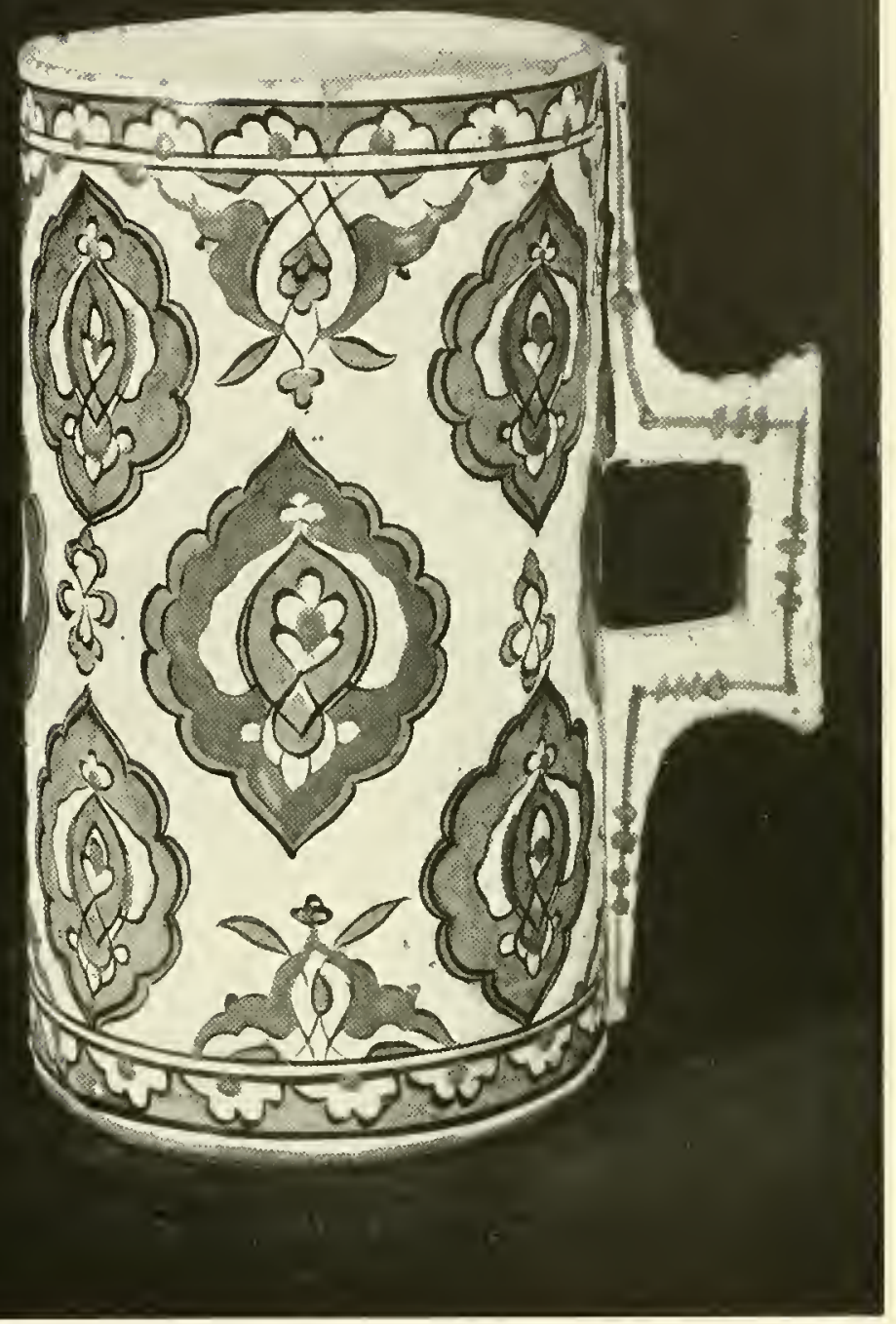




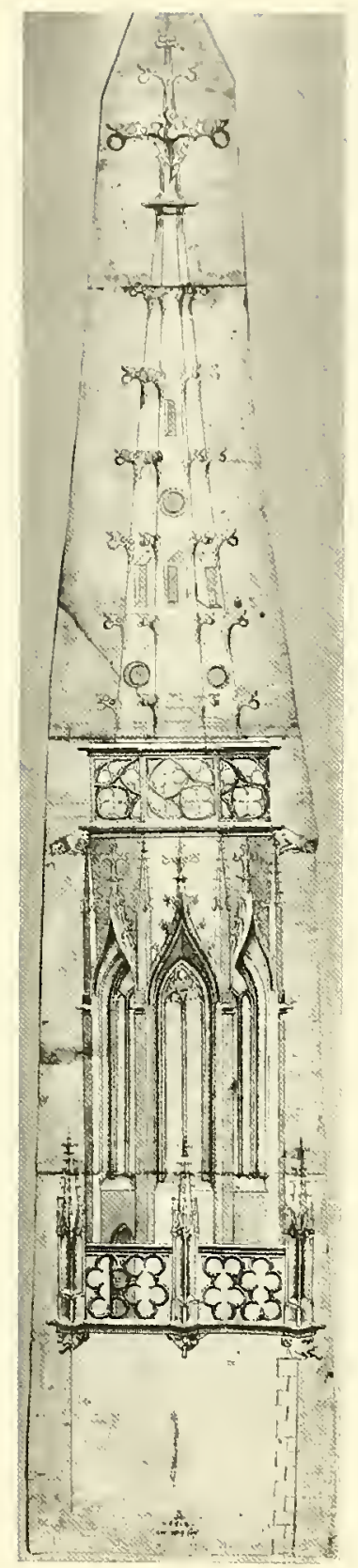

Late Gothic architectural drawings are so rare that this one is the sole example known in an American museum. The essential conditions of such drawings were that they should be perfectly accurate and clear, and those for actual undertakings were usually executed on vellum and of a size larger than this example, carried out with pen and ink with ink wash on paper. Dating probably in the last decade of the $15^{\text {th }}$ century, and of German origin, it is inscribed with the monogram of the workshop, which has not yet been identified, and its suggested size is "200 shoes high." Its shape and proportions seem to indicate the tower to have been for a Rathaus, (town hall), rather than for a church. The drawing may not have been for a specific project, but intended, rather, to illustrate the abilities of the workshop. Of particular interest is the device indicating a quarter-turn by repeating only half a motif, best seen in the quatrefoil tracery of the upper gallery. The execution of the drawing was problably left to a shop assistant, the details of the ornamentation and sculpture being added afterwards by the master, a practice common at that time. This drawing was acquired through contributions by the Friends of the Museum.

R.P.IV.

$53^{1 / 2} \times 10 \frac{5}{3}$ in. $\quad\left[1960-77^{-1}\right]$ 
Diameter, $61 / 2 \mathrm{in} . \quad\left[19^{62-8-1 \mathrm{в}}\right]$

From the gift by Irwin Untermyer of five small embroidered roundels, probably Flemish, 15th century, three have been identified by Miss Margaret Freeman as part of a series illustrating the legend of the martyred Saint Catherine of Alexandria. In the example shown, Catherine has been brought by her jailers to the Emperor Maxentius, who stands before the idol he worships. A similarity to $15^{\text {th }}$ century Flemish painting suggests a design source. Such embroideries worked in colored silks and gold are well named needlepainting for they convey the drana of a moment, the color and flow of rich materials, the grace of gesture. Worn though these delicate embroideries are after almost five hundred years, the felicity of touch of the nameless embroiderer is still apparent. A.B.B.

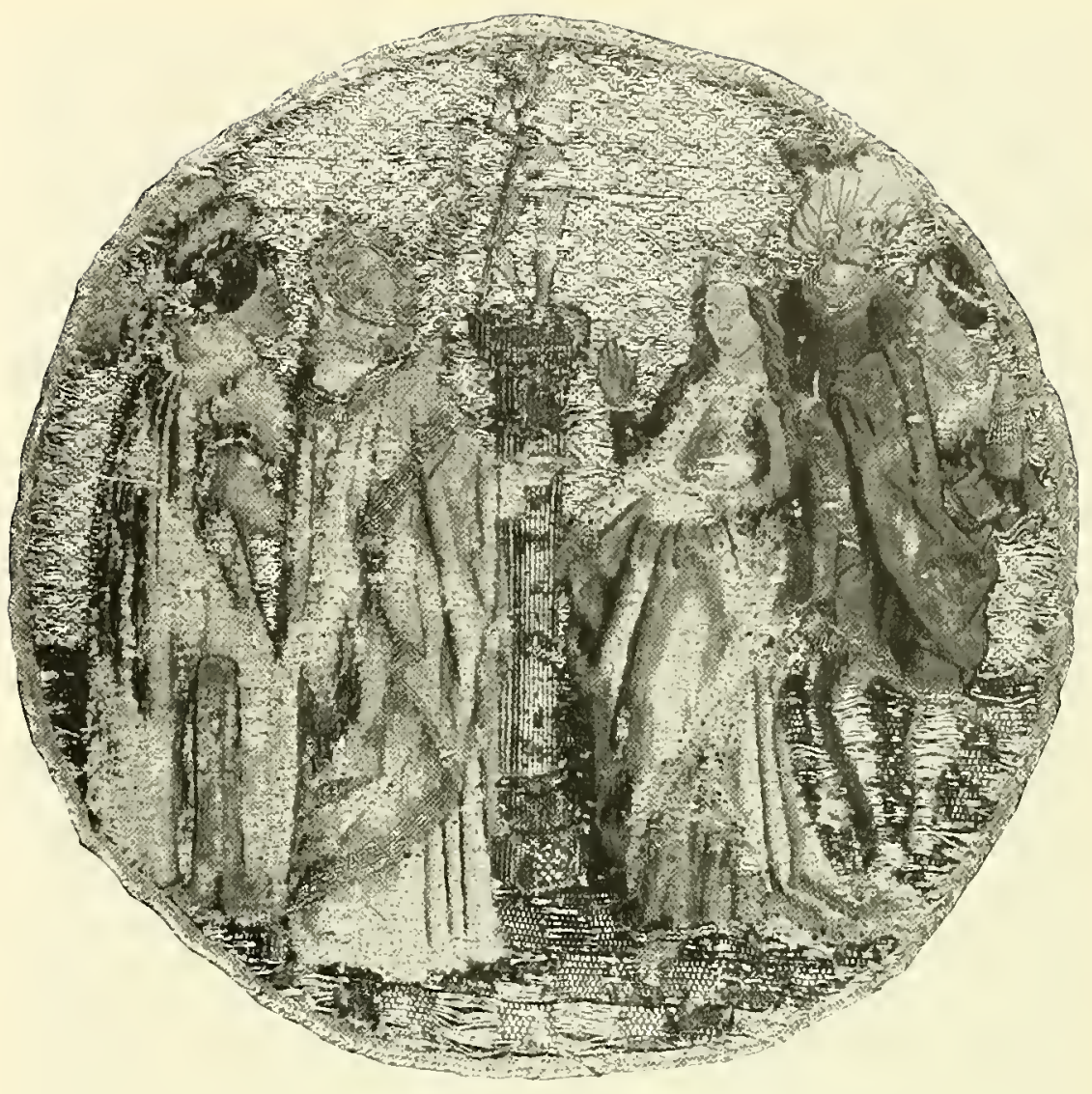




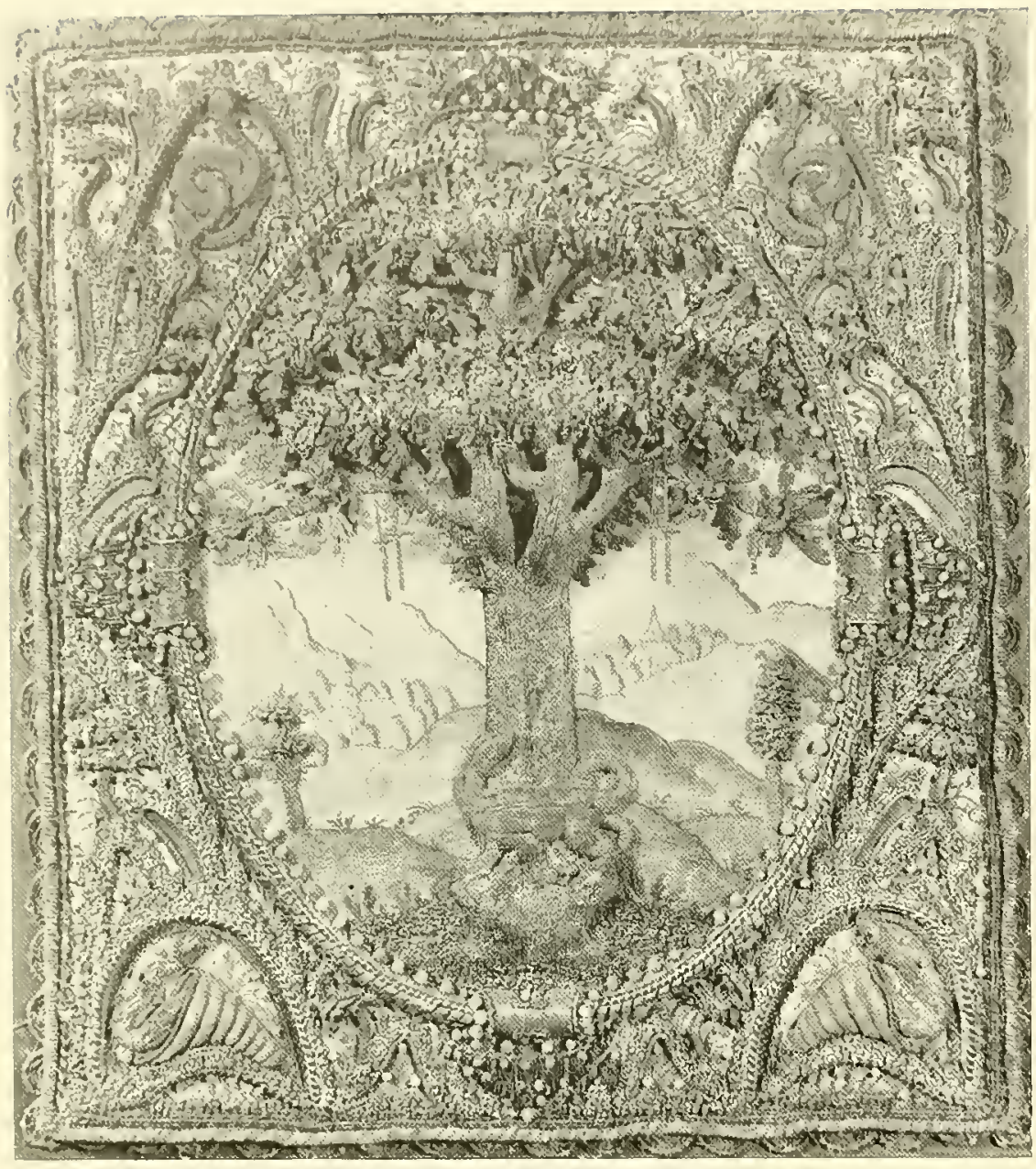

$13 \times 31 \frac{1}{4}$ in $\quad\left[1959^{-1}+4^{-1}\right]$
A pictorial embroidery, possibly French, late 16 th century, formerly in the spitzer and Seligman collections, was given to the Musemm by Miss Marian Hague. Norked in ligh relief on silk in silk and gold threads and coral beads, it presents a curious design, sombre but compelling. The crutches and ex voto objects depending from the limbs of the oak indicate a representation of a votive tree. In the strange elenents of the design appear symbols expressive of myths millenial in origin, transplanted by time into Christian mythology: the tree, symbol of life, of knowledge; at its roots a salamander, believed to withstand fire, expressive of survival; the coral, protection against evil; finally the serpent, in ancient my thologies a symbol of immortality, and as attribute of Asclepius, God of Medicine, the Life-giver, the Restorer, here possibly guardian of the sacred tree.

A. B. B 
While certain craft techniques spread rapidly from area to area and from country to country, others remain fairly localized in their place of origin. In Kireussen, on the German-Bohemian border, and in a few places in Southern Saxony, a rich brown clay was found suitable for the manufacture of jars and tankards. Decorated with lively enamel colors, these renain without parellel in the history of German ceramics. Favorite decorative subjects included the allegories of the Seasons and the Seven Planets, derived from popular engravings by the German Kleinmeister, or from portraits of sovereigns and princes of the Church. Such a pair of portraits adorms two of six panels of this Saxon jar of about 1675 , formerly in the collection of Count Wilczek, of Krenzenstein, Austria, and given to the Museum by Milton J. Blume. The fine repoussé silver-gilt mounts by the Munich silversmitl, Franz Oxner (died I688), testify to the esteem this object enjoyed by its former owners. H. B.

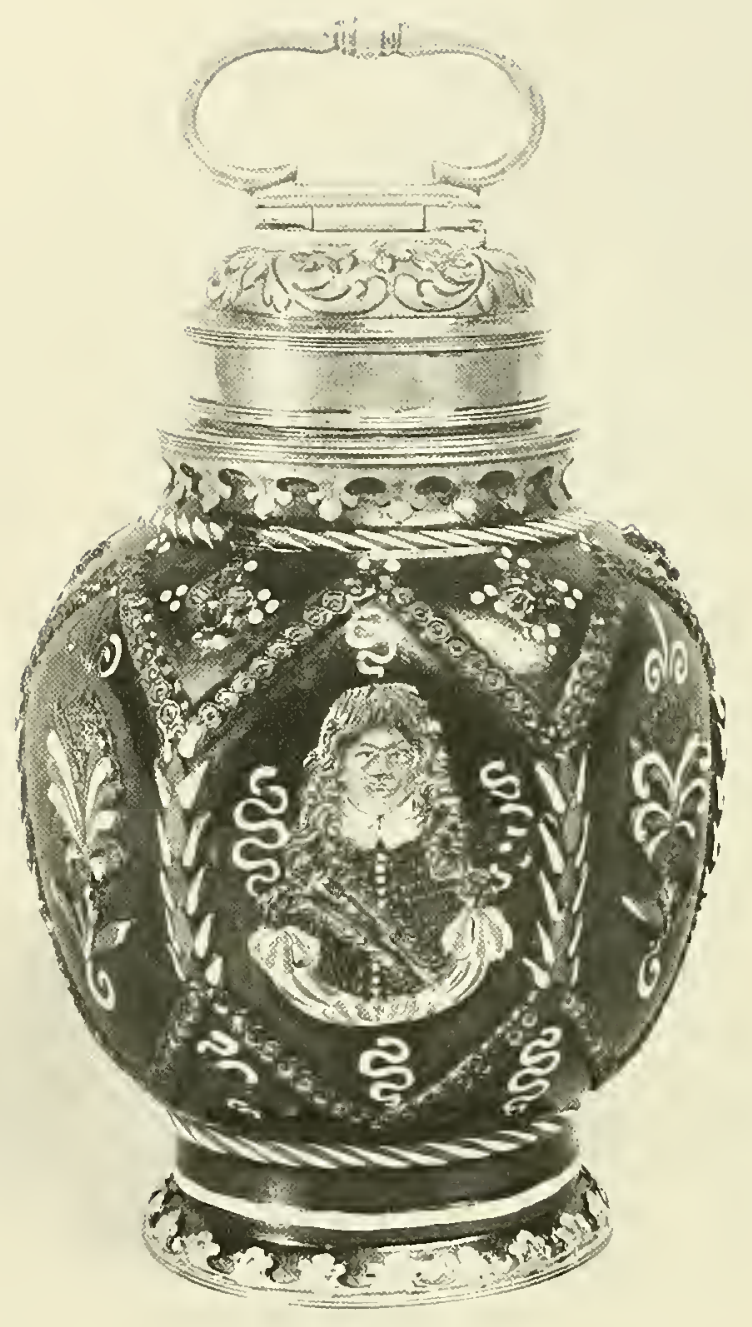

Hcight, $7^{1 / 2}$ in. $\quad\left[1957-174^{-1}\right]$ 


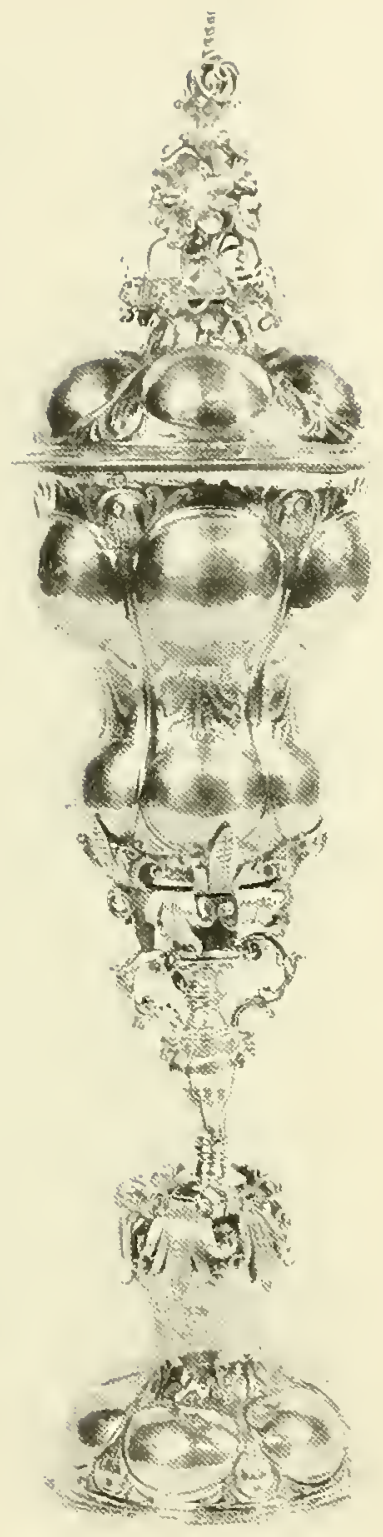

The increasing wealth of luropean cities during the late Renaissance resulted in a prodigious production of expensive showpieces. The German cities of Augsburg and Nuremberg were particularly active in the field of silversmithing, and developed a number of characteristic designs, among then the Buckelpokal, a standing cup with cover, worked in a high bulbous relief and adorned with engraving or other fine details. As further enhancensent, gilding was applied to the silver.

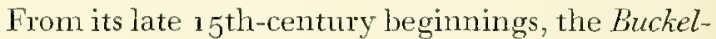
pokal enjoyed great popularity, perhaps owing to the brilliance of light reflections on the raised forms. In this rather small but exquisitely proportioned cup, mid-1 7 th century in date and of Nuremberg workmanship, the characteristic shape is used to exceptional advantage. H.в.

Hcight, $9^{5 / 3}$ in. $\quad\left[1959^{-1} 5^{-1}\right]$ 

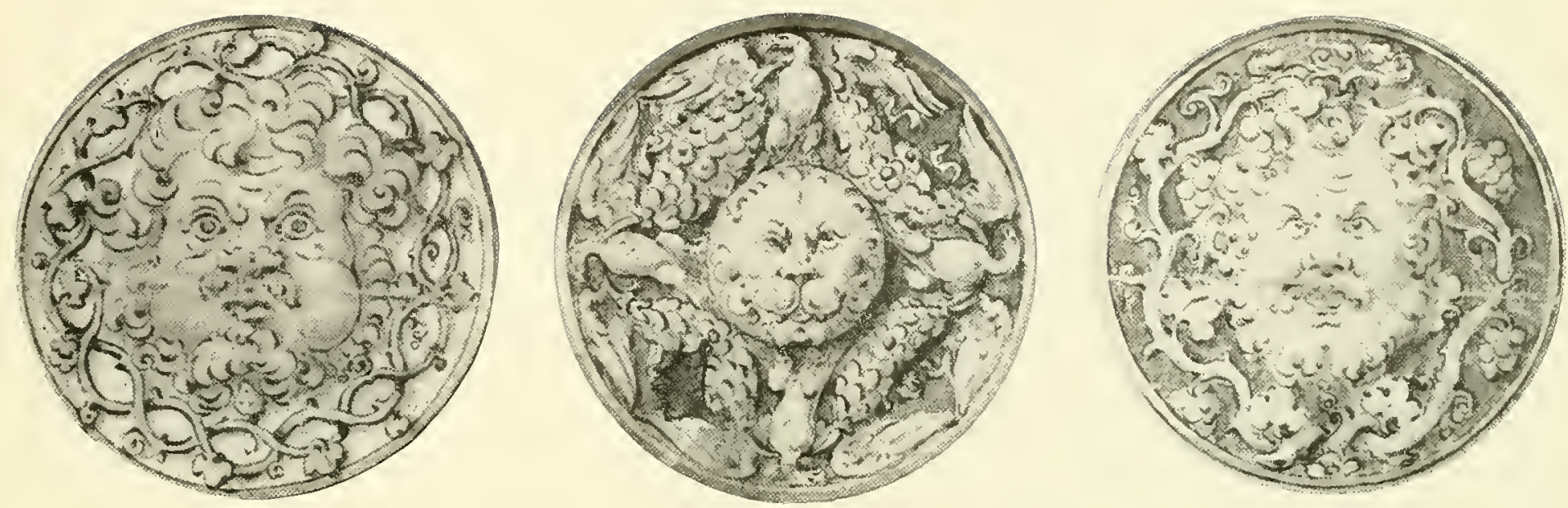

$21 / 2 \times 23 / 8$ in. (each) $[1961-18-1,-2,-3]$

In addition to being a painter and draftsman of Tirst rank, Hans Holbein, the Younger (1497$15+5)$ was also an accomplished designer of ornament. These three roundels, here reproduced in actual size, are executed in pen and brown ink with ink wash, and with the addition of rich blue water-color in the backgrounds of the centre and right-hand drawings. It is possible that the finished objects were intended to be carried out in champlevé enamel on silver, perhaps as ponmels for ceremonial batons. The designs could have been intended also as ornamental adjuncts to the dress of Henry VIII, though they would appear to have been unsuitable for buttons. In character, they relate to the motif of a grotesque head on the hilt of the dagger carried by King Henry seen in the cartoon for the lost Whitehall Palace mural of 1537 , thereby dating the drawings during the last decade of Holbeins's life. These precious drawings entered the Museum's collection through the generosity of Benjamin Somenberg. R.P.W. 


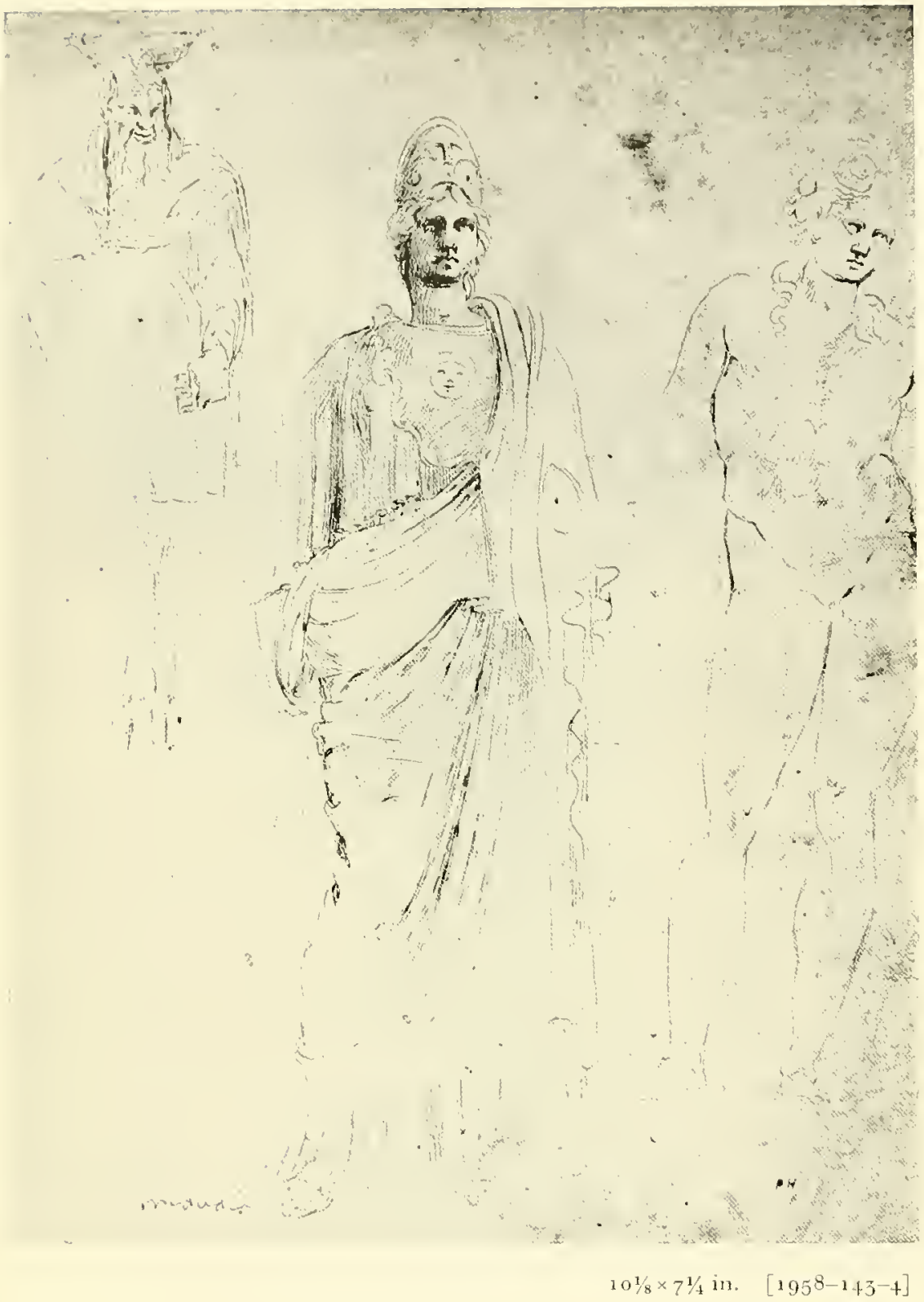

Strongly influenced by classical antiquity during lis sojourn in Rome in the early 1550's, Girolamo da Carpi (1501-1556) filled a number of sketchbooks with drawings of sculpture and grotteschi. This sheet, drawn on both sides in pen and ink with details of classical sculpture, probably comes from one of these books, some of which were dismembered in the 18 th century. The subjects here shown include a herm, a statue of Ninerva and one of a Meleager, and on the verso is the inscription, "delle Valle," a probable indication of the famous Roman collection to which these pieces once belonged. The drawing comes from the collection of Philippe Huart, and was given to the Museum by Hugh Cassel. R.P.w. 
A cap of linen, embroidered in silk, sequins and touches of gold thread, is a rare example of the headgear the Elizabethan gentleman donned in the privacy of his own house. The curious pattern of rainbows and clouds is an illustration of that langnage of emblems to which designers of embroidery often turned in the 16 th and $17^{\mathrm{th}}$ centuries. The rainbow, appearing to Noah as the Flood ceased, became a sign of God's forgivenesshence of peace, of tranquillity. Indeed, it might lave formed part of the heraldic device of the original owner. In the bow we find red, yellow, and darker red and blue. The very curly clouds between the rainbow are in blue outlined with couched gold. The cap, formerly in the collection of George Saville Seligman, is part of the Richard Cranch Greenleaf bequest and is thouglit to date between 1590 and 1610 . A.B.B.

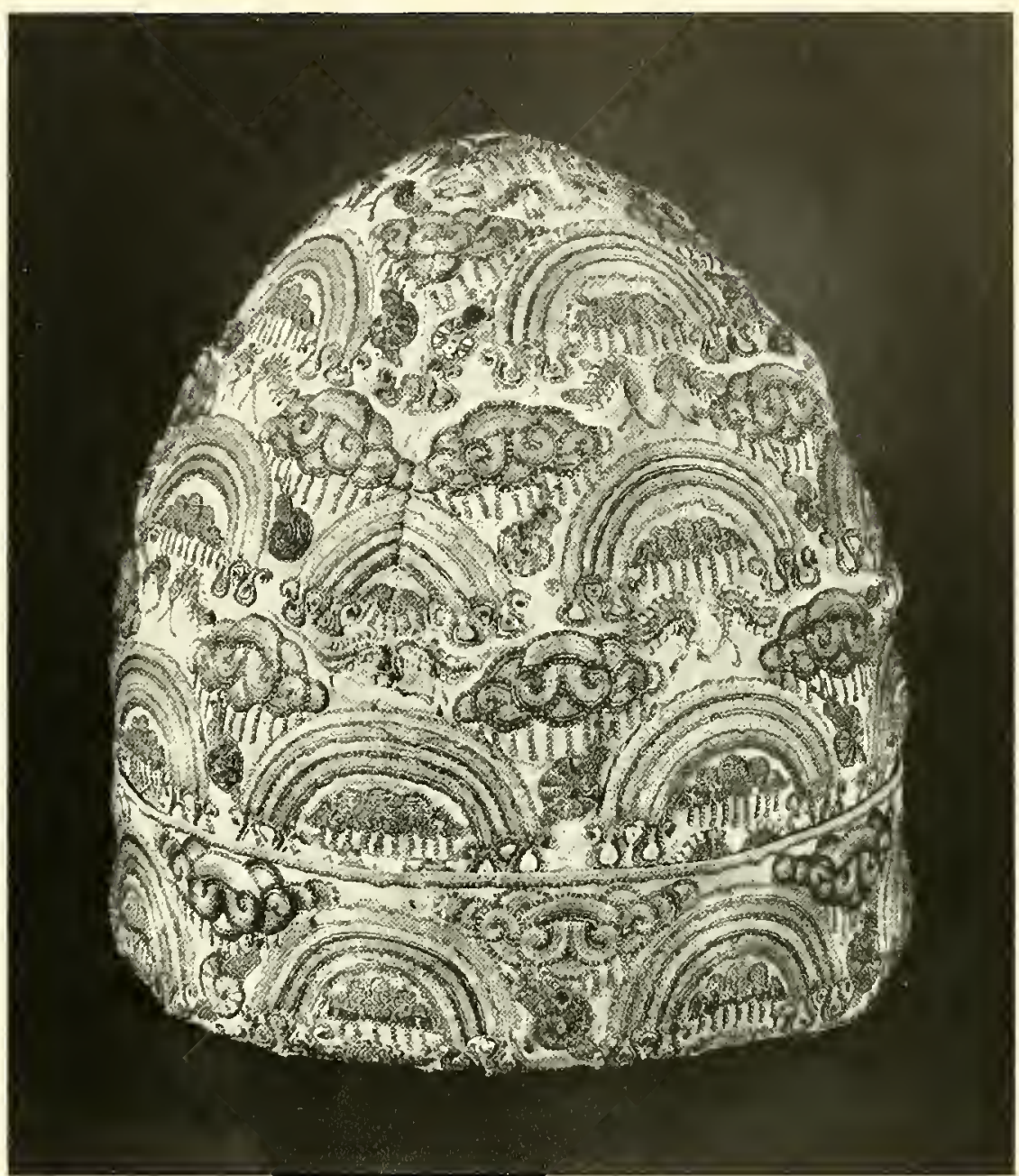

Height, 61/4 in. $\quad\left[1962-53^{-12}\right]$ 


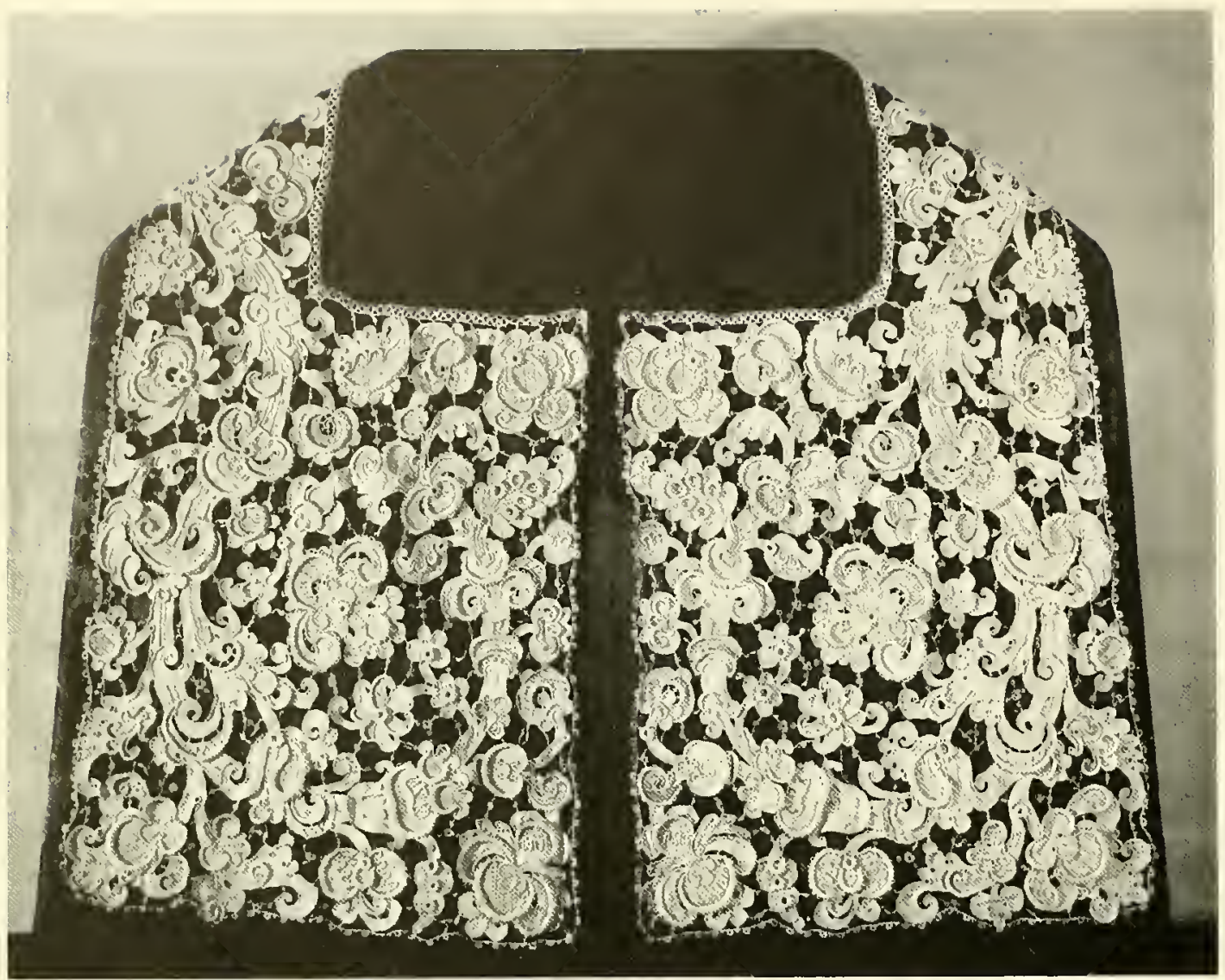

$15 \% \frac{5}{8} \times 15$ in. $\quad[1962-50-28]$

A man's collar of needle lace dating about 1670 from the bequest of Richard Cranch Greenleaf is of a type known as gros point de tenise. It is characterized by its high relief achiever by outlining the pattern with the cordonnet, a cord or thick thread. The design composed of large, freeflowing scrolls, is connected by brides picotées, or tie-bars, decorated with loops simulating pearls in the center of each. Gros point de venise originated in Italy and was introduced into France during the late $17^{\text {th }}$ century by Colbert, chief minister of Louis XIV, from whence it became known as point Colbert. C.C.A. 


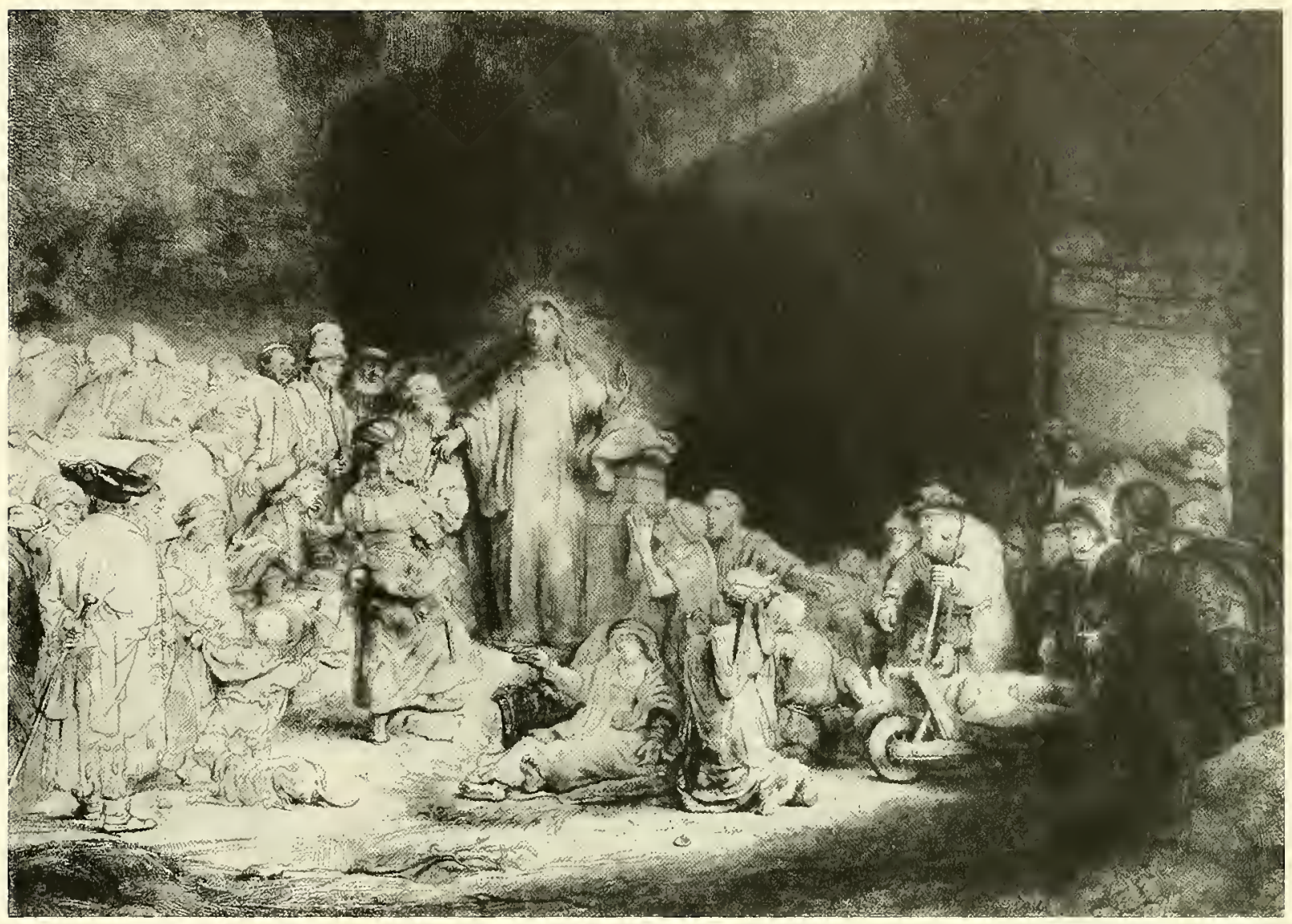

$11 \times 15^{1 / 2}$ in. $\quad\left[1963^{-+3}+1\right]$

The most famous of Rembrandt's etchings, CHRIsT with the Sick Around Him, Receiving Little Children, dating about 1649 , shows more splendidly than any of his other graphic works a singleness of artistic aim fused with trenendous technical virtuosity. Known as the 'Hundred Guilder Print' since the early $\mathbf{1} 8$ th century because of a price it once fetched at auction, the work combines drypoint with etching, and is known in two states; this example is the second, more finished state. Good impressions of this print are of the utmost rarity, fewer than thirty having been recorded. This impression has a most distinguished history. In 1682 it was in the collection of French publisher and art dealer, P.- J. Mariette, and in the igth century passed into the hands of Rudolf Busch, the German industrialist. This famous print joins a group of over a hundred Rembrandt etchings already in the Musemm's collection, gifts generously made over a period of years by the late Leo Wallerstein and continued by Mrs. Wallerstein. R.P.W. 


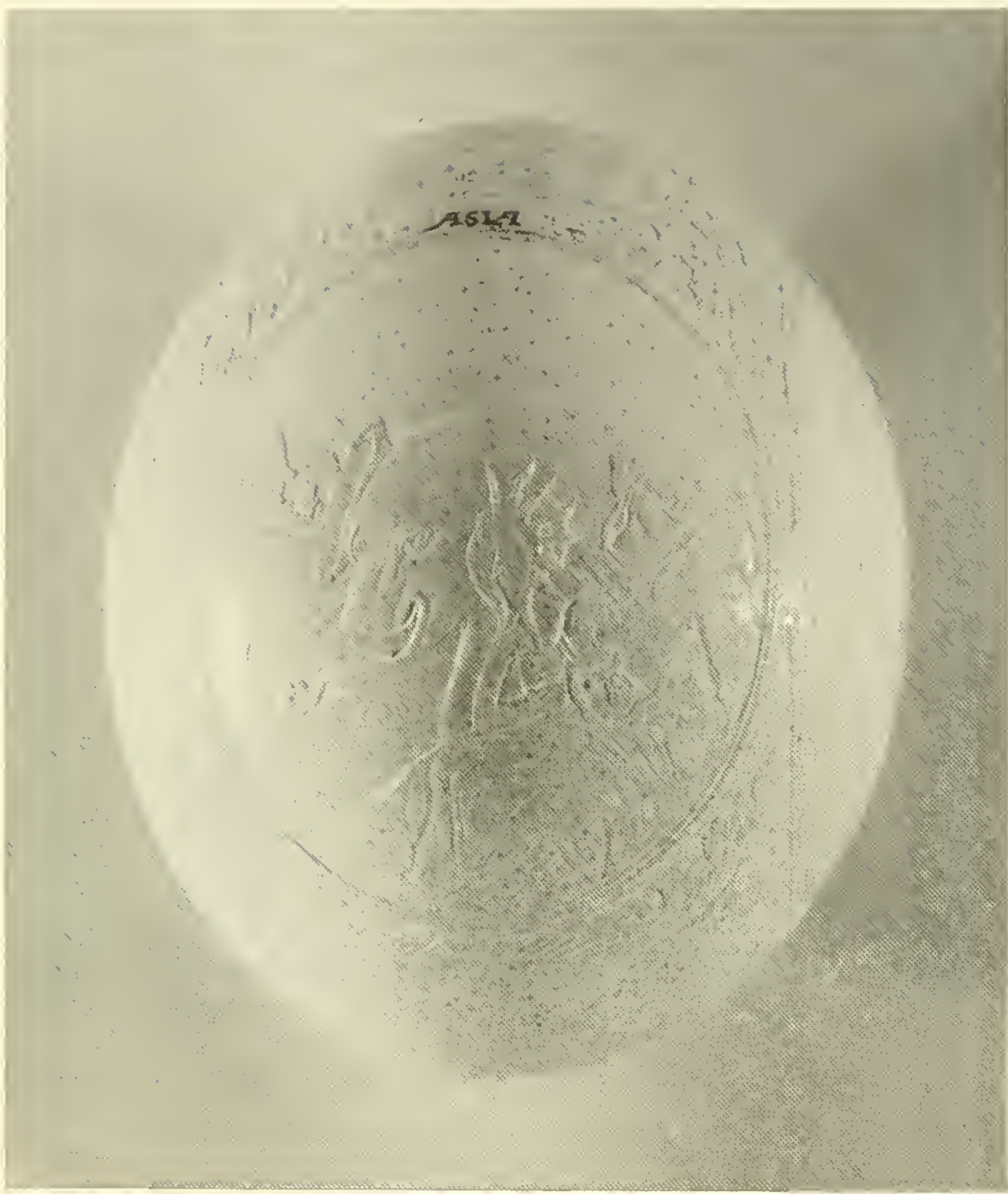

$61 / 8 \times 51 / 8$ in, $\quad\left[19^{60-1-27}\right]$

Strange materials have ałways fascinated Man, and often he endowed them with miraculons properties such as the poison-detecting power of the unicorn's horn. Just as often, Man applied his own skills to improve upon natural materials by painting or carving them. And what would be a more appropriate motif for such an exotic object as an ostrich egg than the allegorical representation of the Four Continents? An engraved New Year's greeting of 1706 from a library in Zurich found its way, as did many other engravings, into a Franconian workshop, where it served as a prototype for the design carved into the fragile shell of this ostrich egg. One of a group of about one hundred and twenty objects with allegories of the Four Continents given by the Trustees of the Estate of James Hazen Hyde, the exotic character of this piece is surpassed perhaps only by another in the same collection, a standing cup carved from the amber-like horn of a rhinoceros.

H.B. 
An object with a closely defined purpose can be as specific in design as its function demands, emphasizing the particular with disregard for general solutions of design problems. In devising this reading chair, all the needs of the literate gentleman have been considered: a comfortably upholstered and shaped seat, intended to be straddled, generous arms on which to rest the elbows, drawers for papers and pens, a retractable candle holder and an adjustable book rest. In a peculiar and functionally sound construction, the back legs are slanted in such a way as to support the weight of the sitter, which is thrown towart the back of the chair. A gift of Mrs. Paul Moore, this reading chair is a fine example of functional design in early 18 th-century England. H. B.

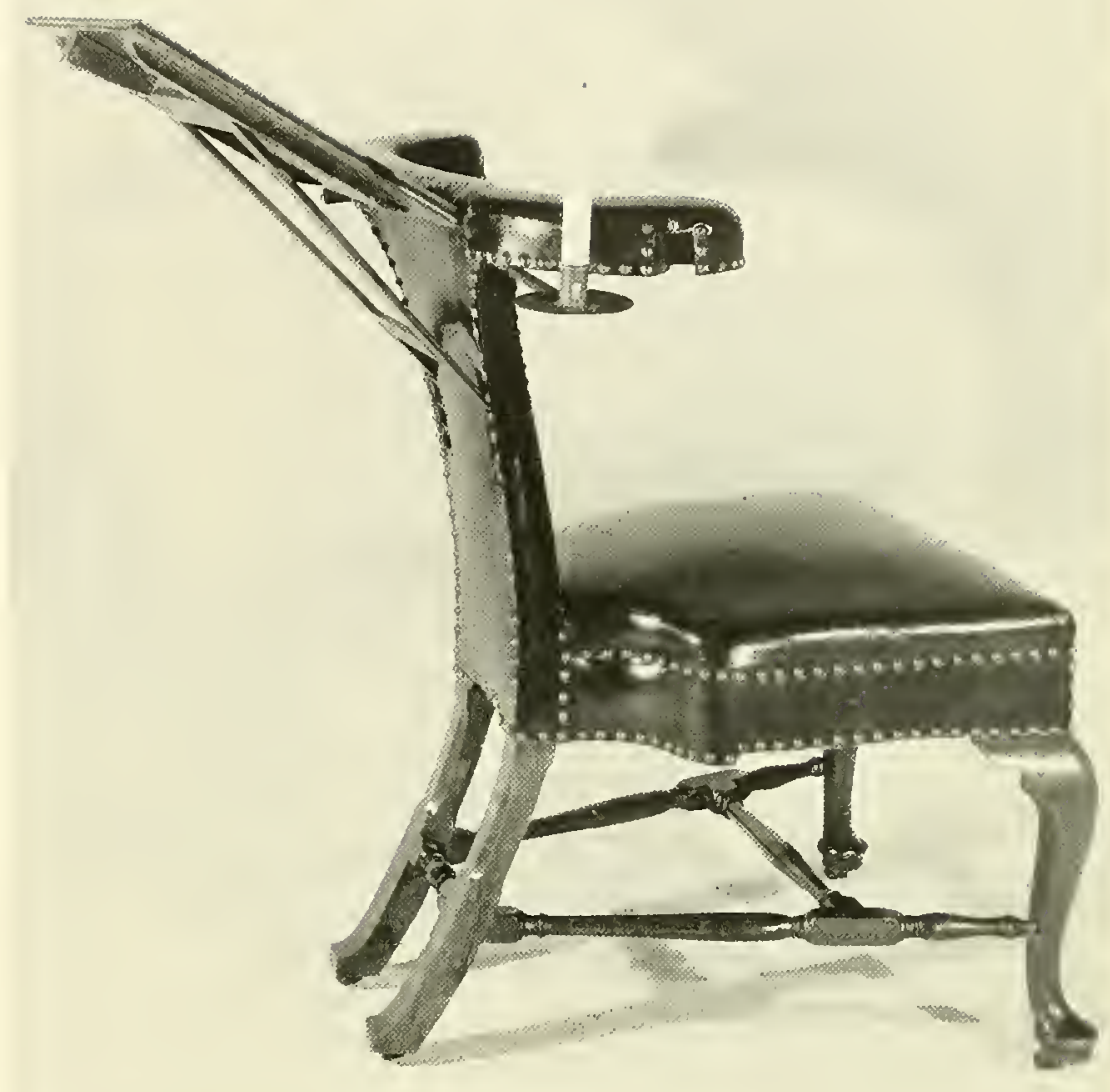

Height, 361/4 in. $\quad[1960-164-16]$ 


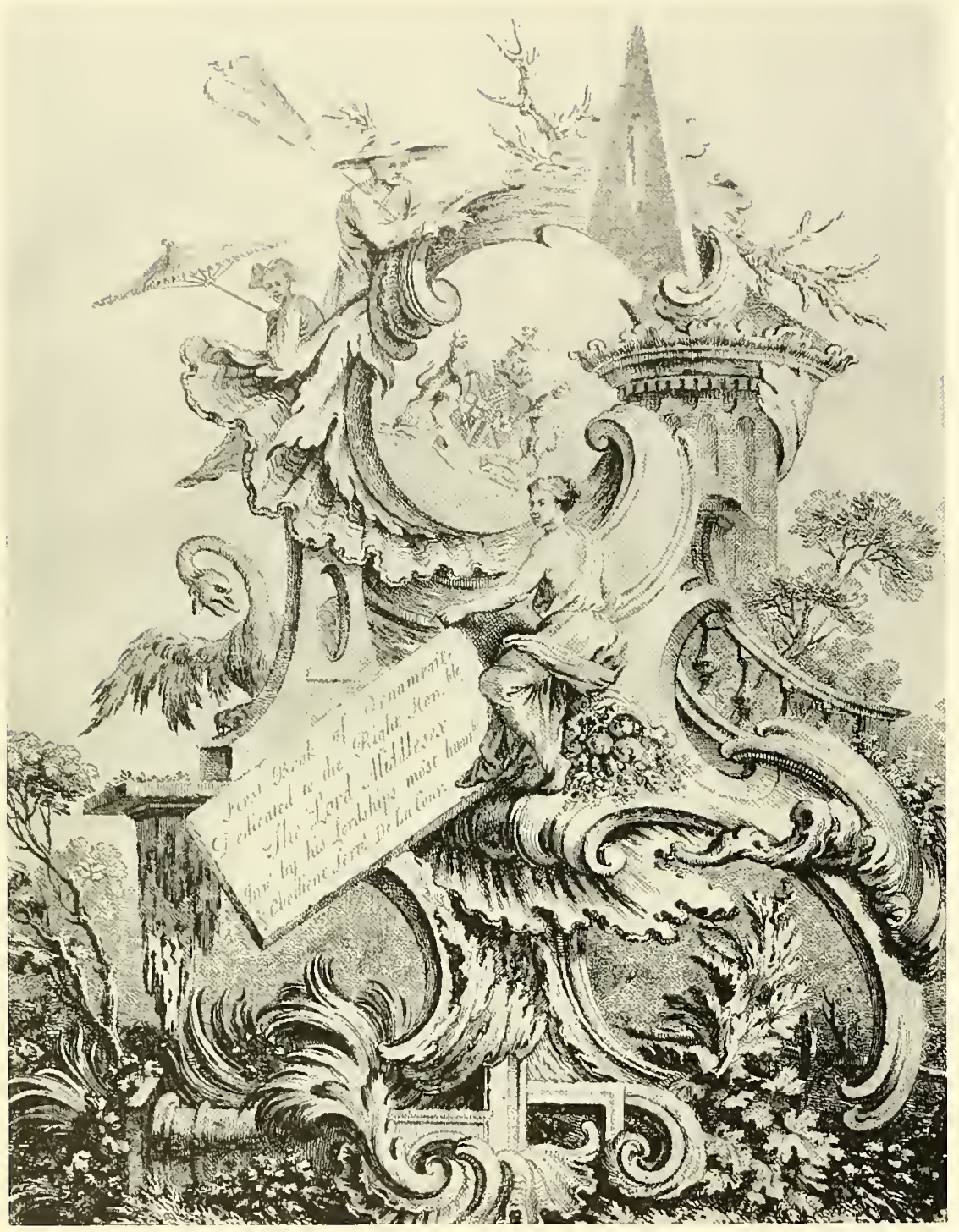

William Detacour, possibly of French origin as his name would suggest, was active in London from $17+1$ to 1767 . He is known only as a designer of eight books of ormament, of which the etched title page of the first book, dedicated to Lord Middlesex, is shown here. Others of the "books" factually suites) are dedicated to the Earl of Holderness and the Duke of Rutland. The Museum is most fortunate in possessing the only known copy of all eight books, bound together, acquired through purchase. Perhaps Delacour was employed by the gentry to whom he dedicated these suites, which include designs for furniture, frames, jewelry, cartouches and other forms of ornamentation. Above all, his designs reflect the then-fashionable French rocoro style of decoration. R.P.W.

$11 \frac{1}{2} \times 8 \frac{1}{4} \mathrm{in}$. (plate line) $\left[19^{62-126-1}\right]$ 
Soon after the discovery of America, the new continent gained entrance into the arts through allegorical representations of the Four Continents. In tapestries and paintings, in silver and porcelain, personifications of the four parts of the world retained popularity with artists for ahnost three centuries. Giaubattista Tiepolo succumbed to their charm, as clict the master-modellers of Meissen. By the mid-18th century at least six different versions were produced at the Meissen factory alone, the most impressive perhaps the one including this figure of AxERICA. The alligator and the parrot were accepted attributes of the New Morld, as was the colorful raiment of feathers. The cornucopia was introduced as an appropriate symbol of the continent from which flowed Mexican silver and Peruvian gold. The set to which this figure belongs was part of the Jannes Flazen Fyde Collection, H.B.

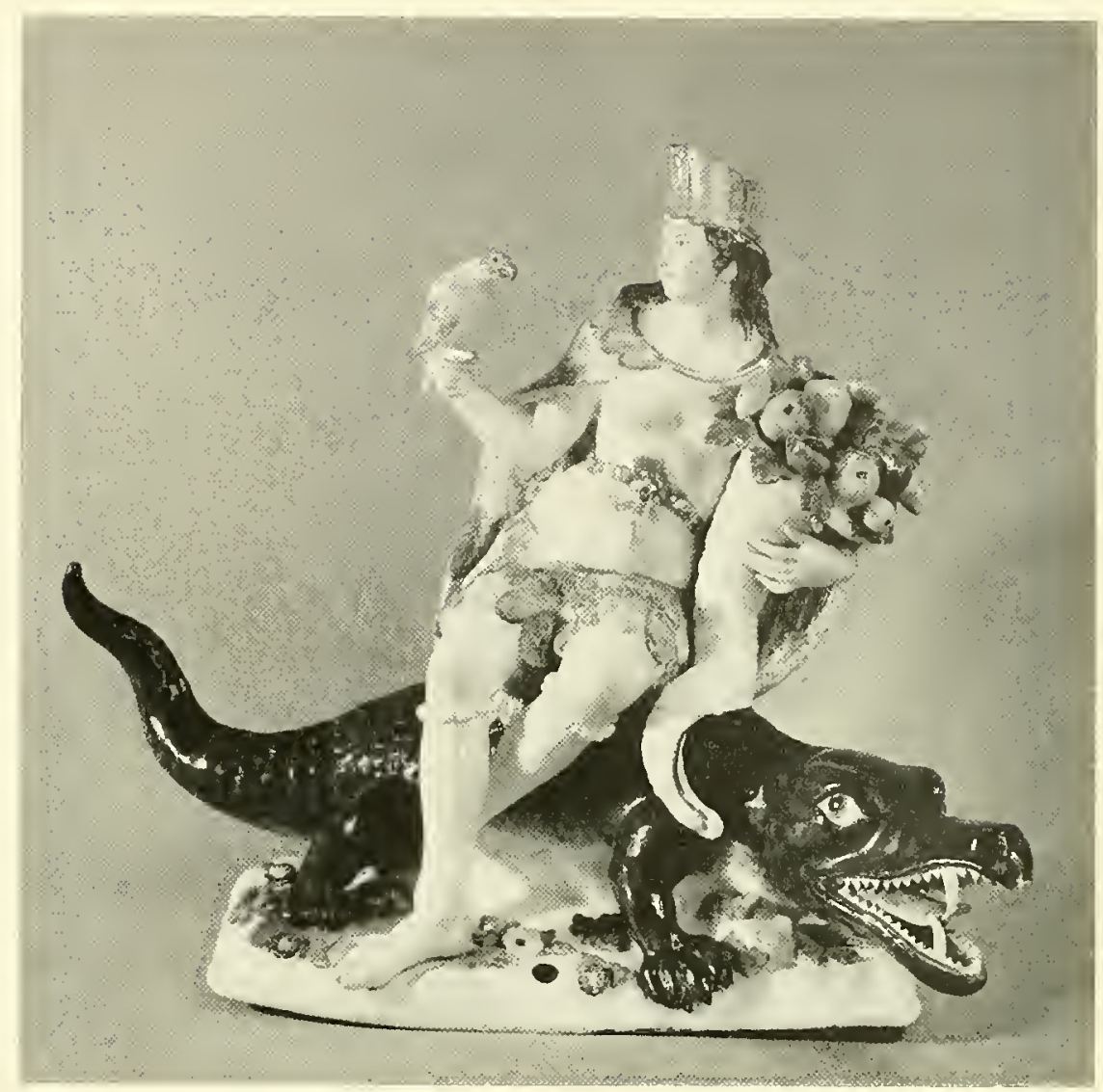

Height, $10 \frac{5}{8}$ in. $\quad[1960-1-28, \mathrm{D}]$ 


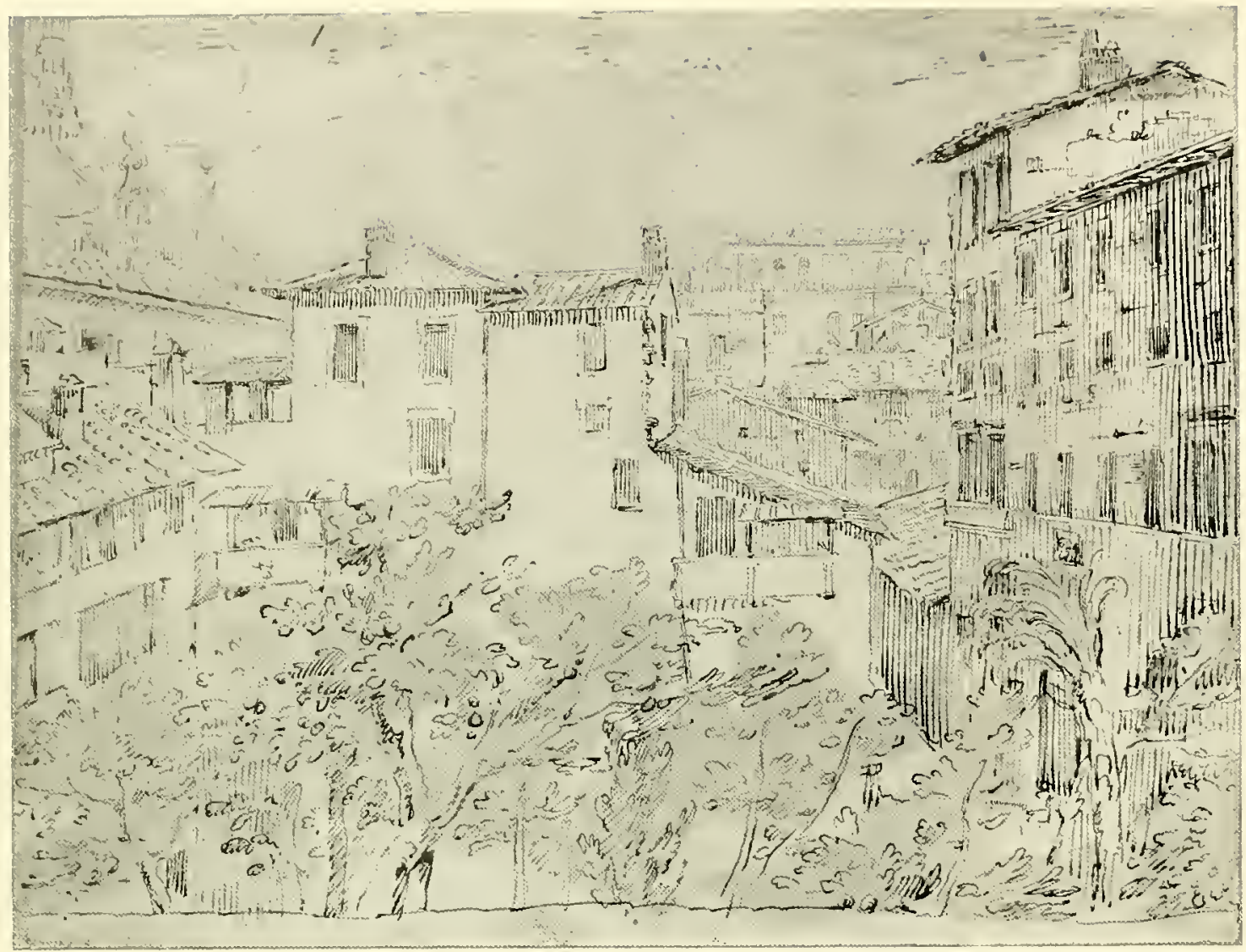

$81 / 4 \times 10^{3 / 4}$ in. $[1960-102-19]$

During his student days in Rome in the 3690 's, the eager young French architect, Filles-Nlarie Oppenord (16-2-174.2) filled a number of sketchbooks with drawings of Roman architecture, sculpture and painting, interspersed with his own desigus for architecture and ormament. The lessons which he thus learned were later incorporated into his own work in Paris which became the basis for tlıe Régence style. The Museum was most fortu- nate to be able to acquire through purchase an album of Oppenord's Roman sketches, in which are included all phases of his varied work. This sheet, executed in pen and ink with delicate watercolors, is a view from the artist's own window looking toward the Palazzo Lante, with a glimpse of the curved roof of the Sapienza chapel at the left. Due to modern building activity, this view no longer exists. R.P.W. 
The graphics collection of the Museum, exceptionately rich in the decorative arts, possesses a few rare watercolor drawings from the porcelain factory of Sèvres. For some years, a saladière of generous proportions, corresponding exactly to one of these drawings, was in the collection of the late Captain John Jay Ide. Recently it has been reunited with the original design through the generosity of Mrs. Ide, as a gift in memory of her late husband. The soft paste of the decagonal bowl, of a pleasing warm white color, is decorated with multi-colored flowers by Jacques Mlicaud, whose mark and the date letter for the year 1765 are to be found on the bowl. H.B.

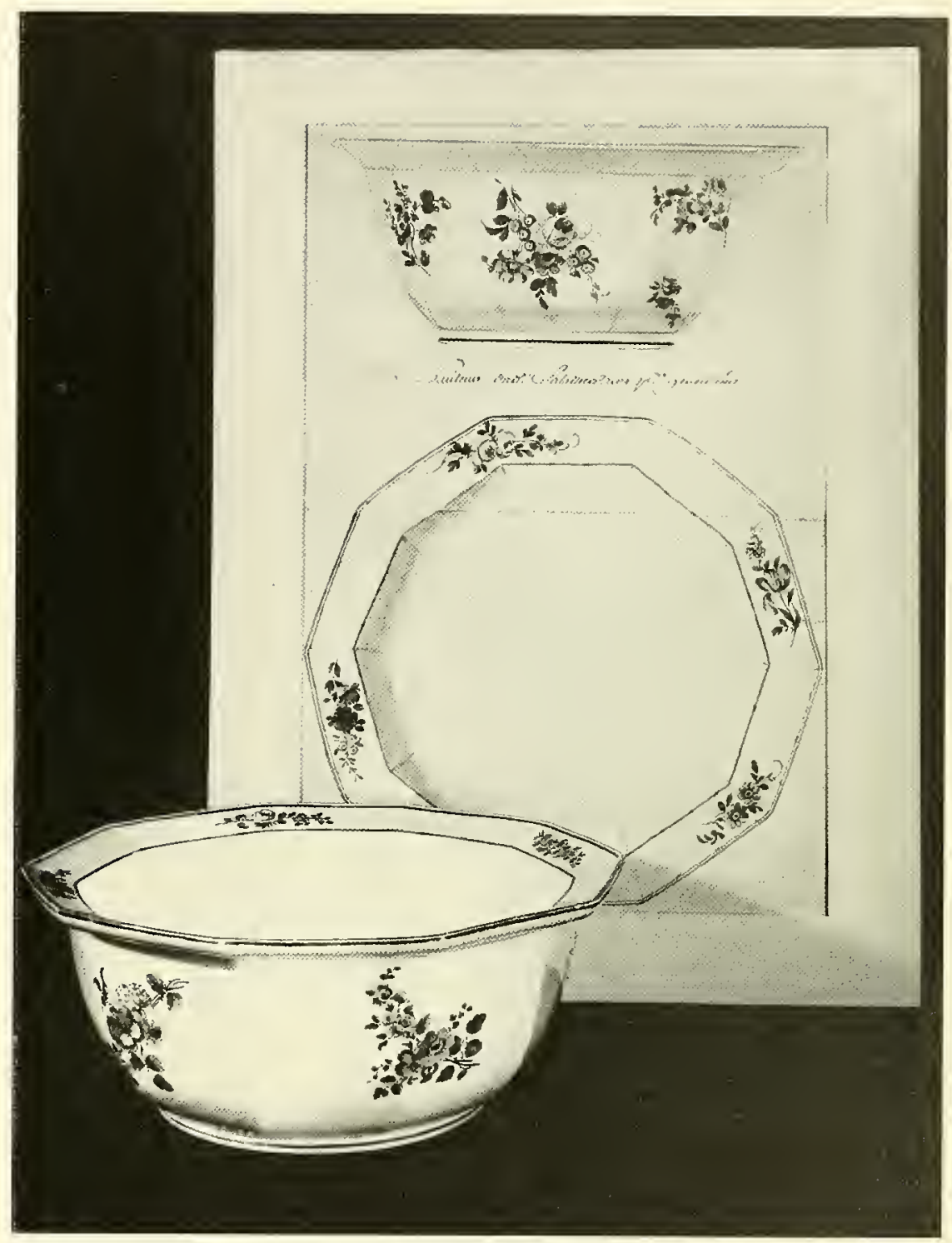

Bowl: $11 \frac{1}{2}$ in. (diameter) [1963-75-1]

Drawing: $16 \frac{1 / 2}{2} \times 12 \frac{1 / 4}{1}$ in. $\quad\left[193^{8}-88-85_{10}\right]$ 


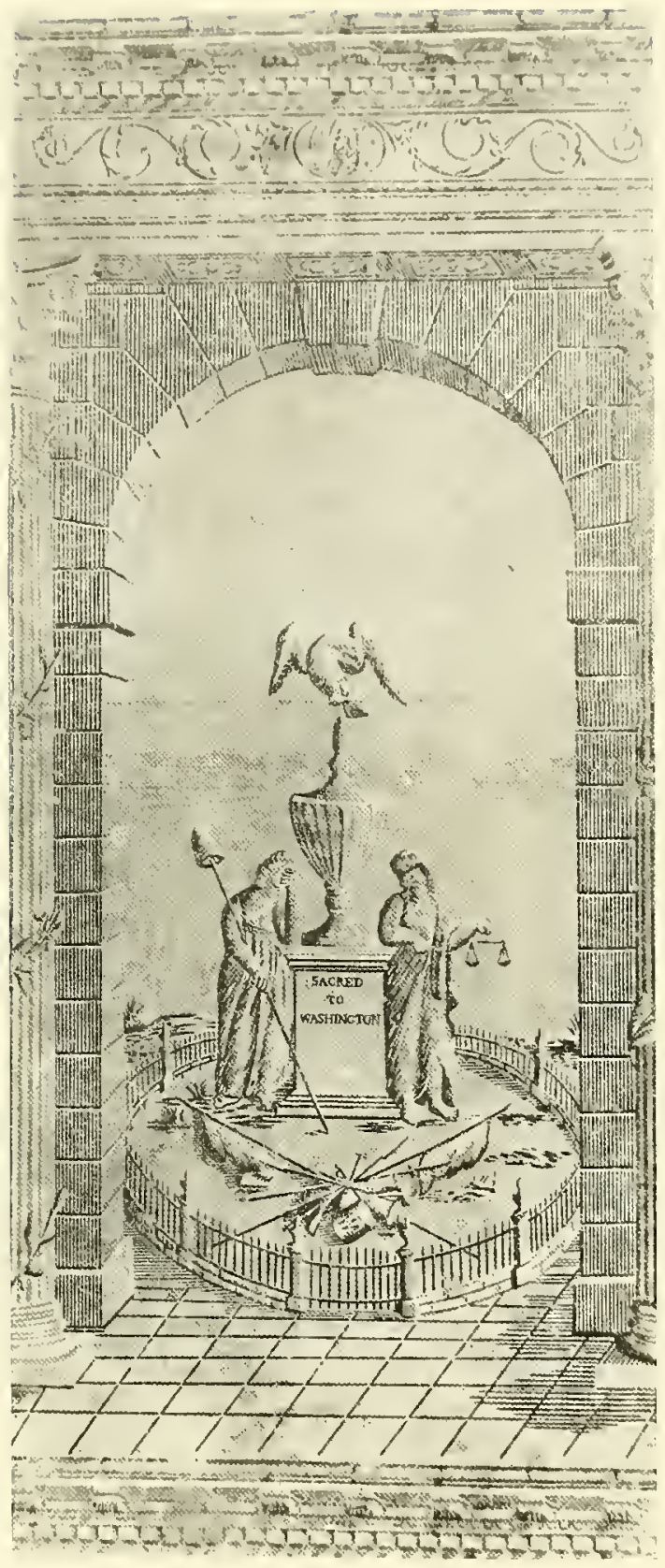

Height, 47\% in. [1960-10 -1$]$

The Anerican production of wallpaper was heralded by an advertisement of Plunkett Fleeson in the Pennsylvia Gazette as early as 1,56, but few papers of early domestic manufacture can be identified as being by known paper stainers. In the case of this wallpaper, commemorating the death of George Washington, the authorship seens to be undisputed. Ebenezer Clough, paper stainer of Boston, produced it in 1800 , incorporating in it architectural elements popular in the late 18 th century, and mourning figures symbolizing Freedom and Justice. Undoubtedly the timeliness of the design appealed to the patriotic feelings of the young Republic, grieving for its Revolutionary hero and first President. A gift of the children of the late Mrs. Edith Parsons Morgan, this wallpaper is a rare and interesting example from the Museum's extensive collection of historic wallpapers. H. B. 
To the touch and to the eye, a raw plank or masonry wall suggests little of the warmth and comfort which make a house a home. At an early stage, Man began to improve on basic building materials by coating or covering the interior walls with more refined surfaces, providing not only tactile but also visual pleasure. The figured tapestries of the rich had their counterparts in painted hangings, like this bonad from a Swedish farmhouse. Such peasant paintings usually showed biblical scenes, mirroring in dress and details the familiar world of the village. Bright colors and an unmitigated horror vacui add considerably to the effect of appealing naiveté. This early $19^{\text {th }}$ century wall hanging, one of a group of twenty given the Museum by the late Richard Cranch Greenleaf, represents three independent scenes: The MARriage at Cana with the Miracle of the Wine, Hagar in tHe Desert, and David AND GoLIATH. H.в.

Height, $461 / 2$ in. $\quad[1959-140-6]$

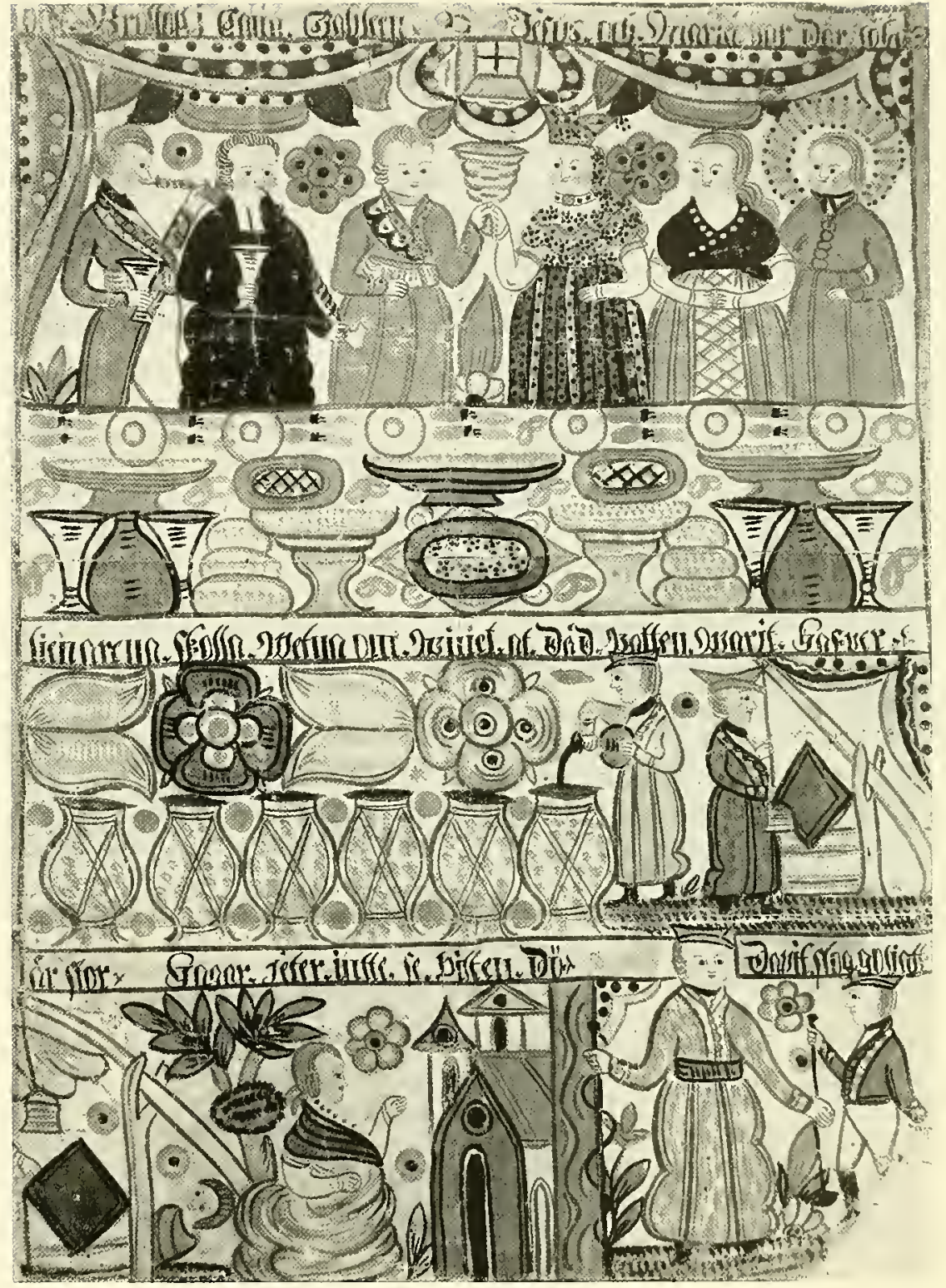




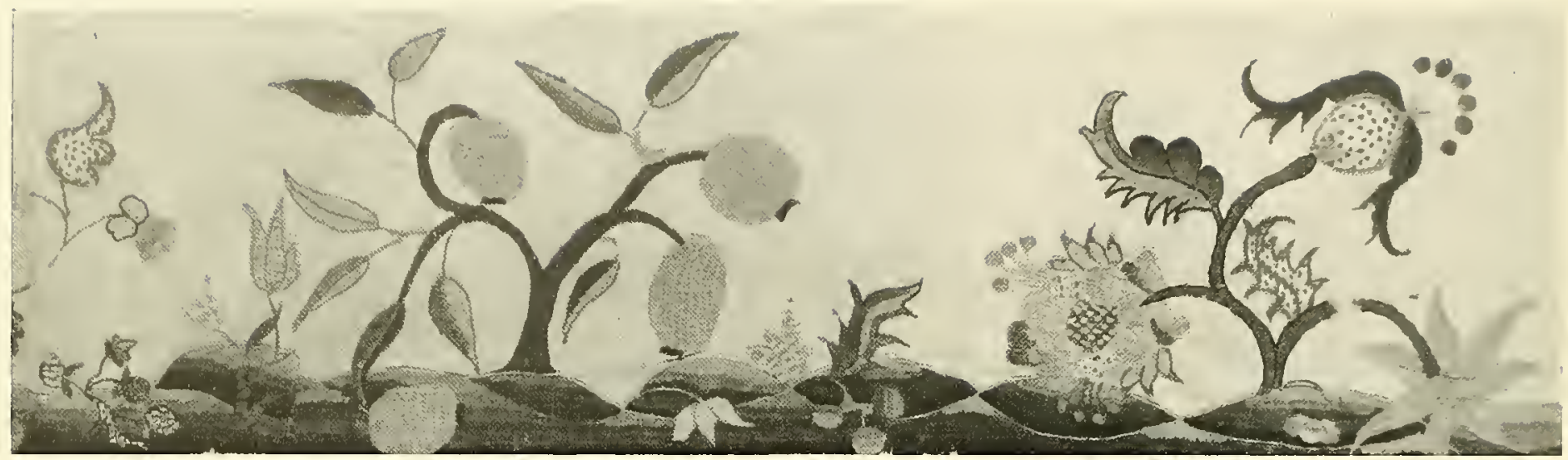

$29 \times 6$ in. (detail shown) $\left[19^{6} 1-7^{-1}\right]$

Crewel embroidery in 18 th-century America, offshoot of similar English embroidery of the $17^{\text {th }}$ century, attained a character of design and technique all its own. This embroidered border of a woman's linen petticoat, aequired through the generous assistance of Mrs. Alastair B. Martin and the late Mrs. Montgomery Hare, is a delightful example of the originality and curious unreality of such designs. Although the foreground is more or less typical of both English and American pat- tern, the forms of the dwarf txees with vigorously curving branches, the oversize fruits and blossoms, the fresh, strong colors, often in sharp contrast, the very economy of wools, and the open background, mark the dissimilarity to the heavier English work. The lemon tree, with its balloon-like flower, has a red trunk, parti-colored leaves, sharp yellow fruit, while in the neighboring tree a deliciously eccentric yellow starfish-shaped blossom bends to the ground. A.B.B. 


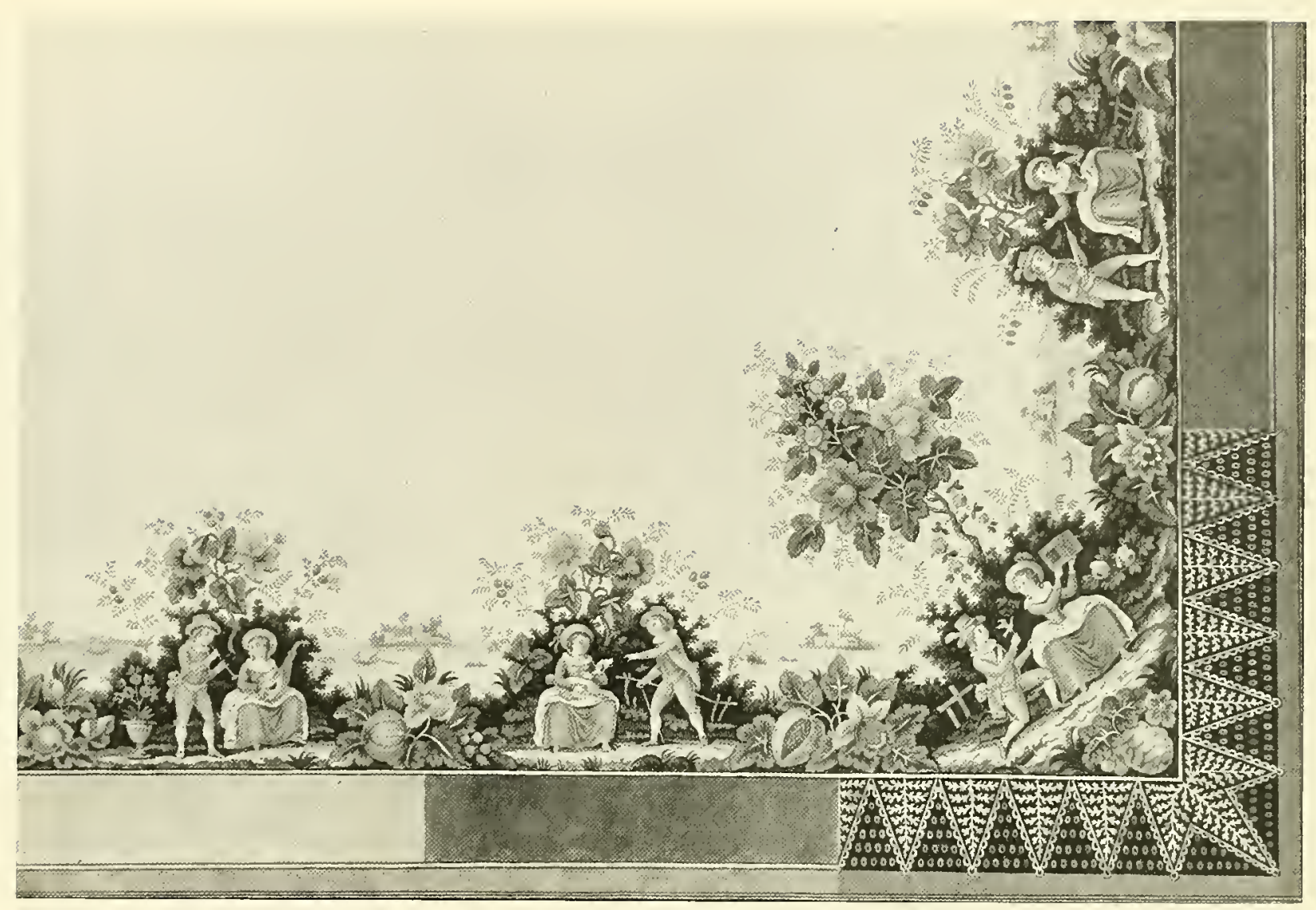

$16 \times 21 \frac{1 / 2}{2}$ in. $\quad\left[1957-4^{6-2}\right]$

With the increased demand for inexpensive rollerprinted cottons toward the end of the 18 th century came a fad for gaily colored kerchiefs, A wellknown manufactory for cotton printing was that of Fazy et Compagnie, located in Geneva. The Fazy works were served, for the most part, by a family of designers by the name of Dubois. This drawing, in brilliant watercolors, is by one of the younger nnembers of the family, Louis-Albert
Dubois $(1752-1818)$. The drawing may be dated about 1801 . The scene suggests the environment of Lake Geneva, dotted with small islands and bordered by low hills that rise in the neighborhood of Lausanne. The large group of textile designs by various nembers of the Dubois family, to which this example belongs, was acquired through contributions by the Friends of the Museum. R.P.W. 


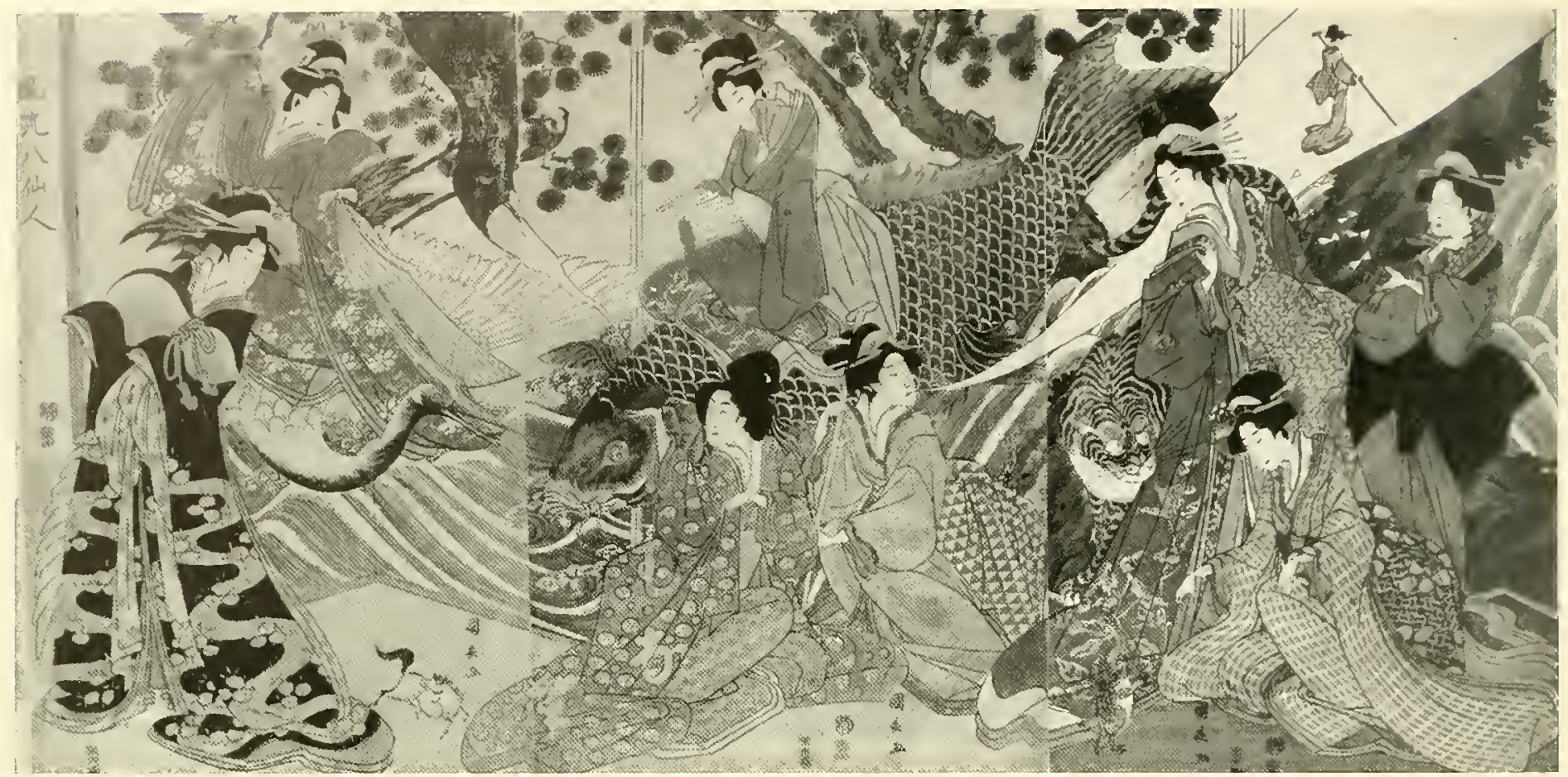

$14^{3 / 4} \times 29 \frac{1 / 2}{\text { in } . ~} \quad\left[1963^{-12-1}\right]$

One of the most intinuate and ready contacts with Japan may be acquired through the engaging study of the numberless colored woodblock prints of the so-called Ukivo-e School that flourished from the early izth century until the fall of the Tokugawa Dynasty in the mid-1 gth century. This triptych by Kininaga, who died abont 1820 , represents a conposite scene from a Kabuki drama concerning the Eight Sennin (Tmmortals). The characters include Kinto on a carp-steed, Oshikyo riding a white crane, Chokiwaro holding a gourd from which she conjures a snuall horse, and Chinnan holding a bowl from which issues a column of snloke enveloping a dragon. At her right sits Tekkai breathing forth a dininutive reproduction of herself, and facing her stands Korejin with her tiger companion, near which is seen Chokiuka cutting fragments of cloth from her garments and tossing them into the air where they instantly turn into butterflies. Finally, below, Gaga kneels and plays with her fabulous toad. Apart from the complicated composition, the patterned relationships of line and color reached a degree of refinement with the art of Ukiyo-e rarely surpassed in Oriental graphic art. R.P.IV. 


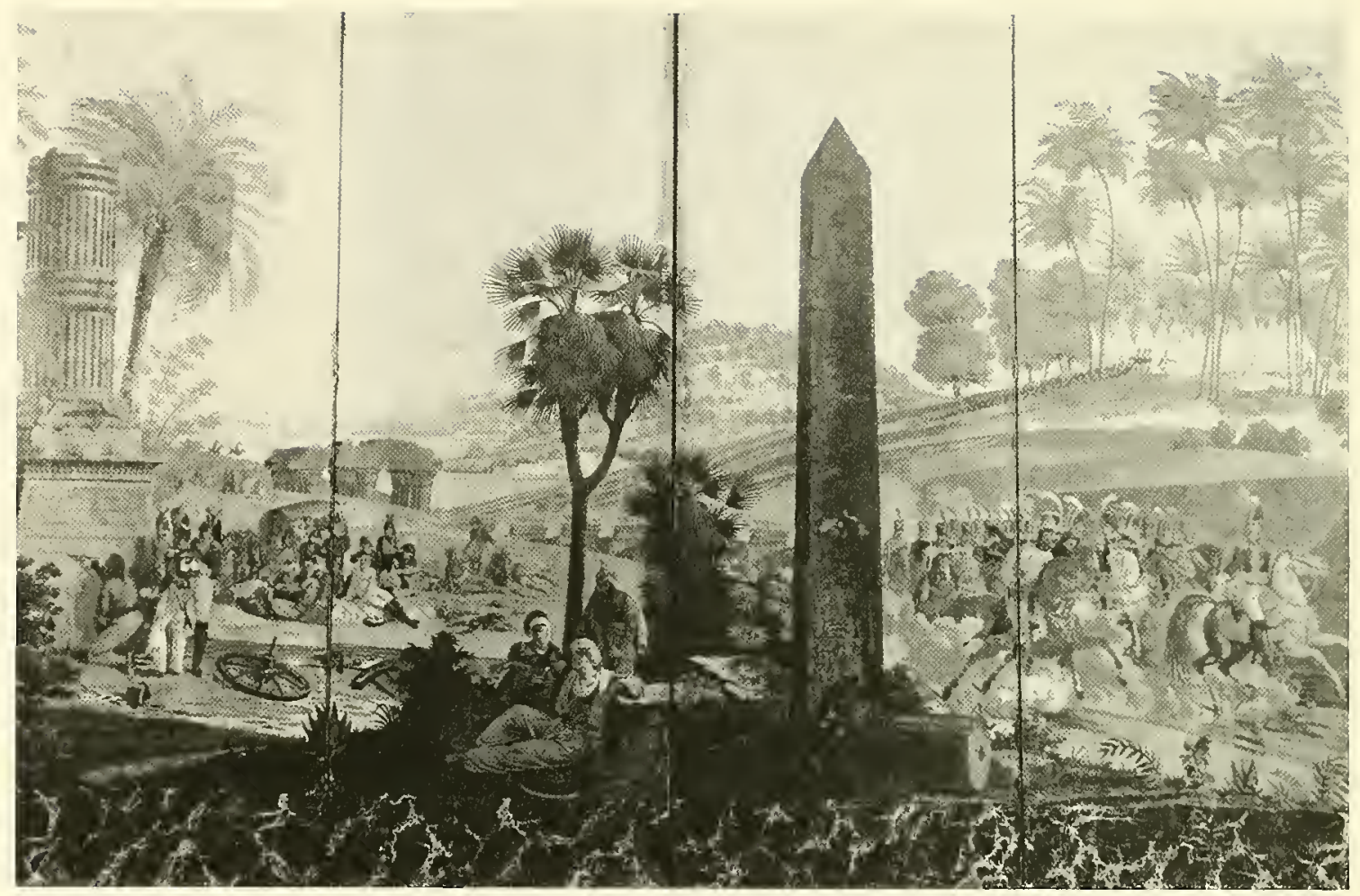

$91 \times 121 \mathrm{in.} \quad[1960-12-1]$

From the late 18 th century through the first half of the r gth a happy collaboration existed between artist and wallpaper manufacturer, resulting in significant innovations. Perhaps inspired by the panoramic paintings then in vogue on the amusement strips of the Paris boulevards, artists worked out cartoons for wallpapers with non-repeating designs. A continuous scene, or a series of connected scenes, formed the complete décor of a room, providing illusionary vistas into distant, often exotic landscapes, or illustrating episorles from mythology or history. Thousands of woorblocks were necessary to produce this paper of about 1814 by Jean Julien Deltil. Entitled Lis Fr.sCAIS EN EGIPTE, the inscription on the base of the broken columm at the left reads: "Le no Mars 10,00o Français Commandés par le Brave Kléber ont vaincu 80,000 Turcs dans les plaines d'Iléliopolis." This section, made into a four-panel screen, is the gift of F. Burrall l Joffman. H. B. 


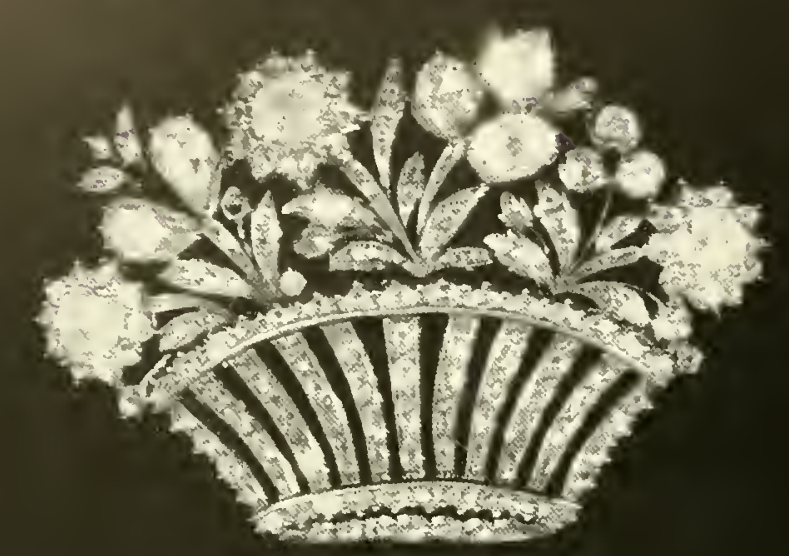

$5 \times 21 / 8$ in. $\quad\left[19^{62-26-1}\right]$

Along with a diverse collection of designs for jewelry, the NTusem possesses interesting examples of original pieces, one of which is the brooch shown here in actual size. The piece dates from the second half of the 18 th century and is thought to be either English or French. Of superb craftsmanship in design and execution, it is composed of rose-cut diamonds set in silver and gold, arranged to form a basket filled with floral sprays. Whether or not its original use was as a brooch, or as the center part of a tiara, remains a question. This piece was given by Miss Gertrude Sampson.

C. C. M. 
This tiny bird, covered with brilliant hummingbird feathers, is housed in a tortoise-shell box witl a silver-gilt lid. When the lid snaps open, the bird rises through a chased grate, flaps its wings, moves its beak, twitters a brief enraptured song, and disappears again beneath the closing cover. The fascination for movement in art goes back much further than the late $19^{\text {th }}$ century inventions of the Lumiere brothers. During the Renaissance, the popularity of automatons for the amusement of kings and princes was rivalled only by the live entertainment in mascues and cortèges. Elaborate mechanisms were devised to lift, pull, turn, play a tune, or perform some other mechanical miracle of playful invention. With their fine sense for minute mechanical detail, the Swiss supplied many automatons with their inner works, althougl the outer casings may have been made in other countries. This artful piece of 18 thcentury mechanical entertainment was given by Mrs. Jolın D. Rockefeller, Jr. H. B.

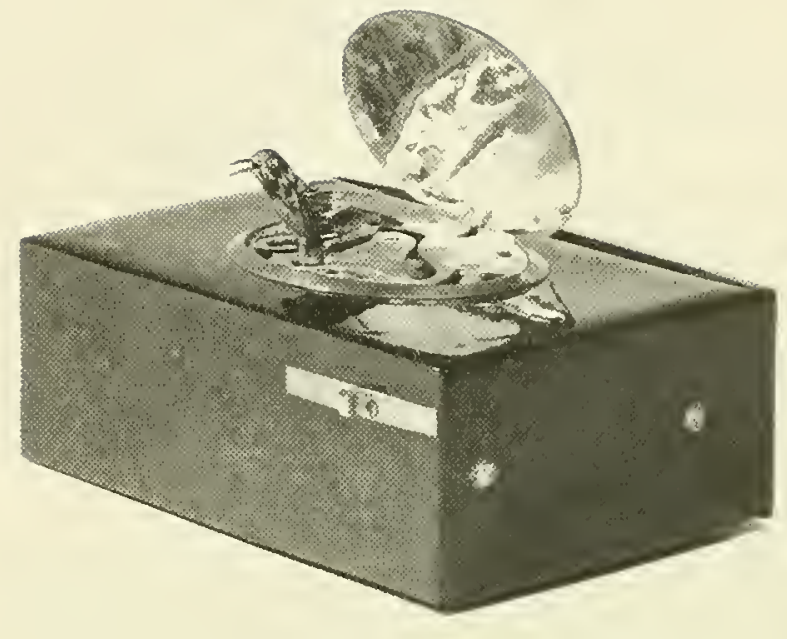

Height $($ closed $), 11 / 4$ in. $\quad\left[195^{8-42-1}\right]$ 


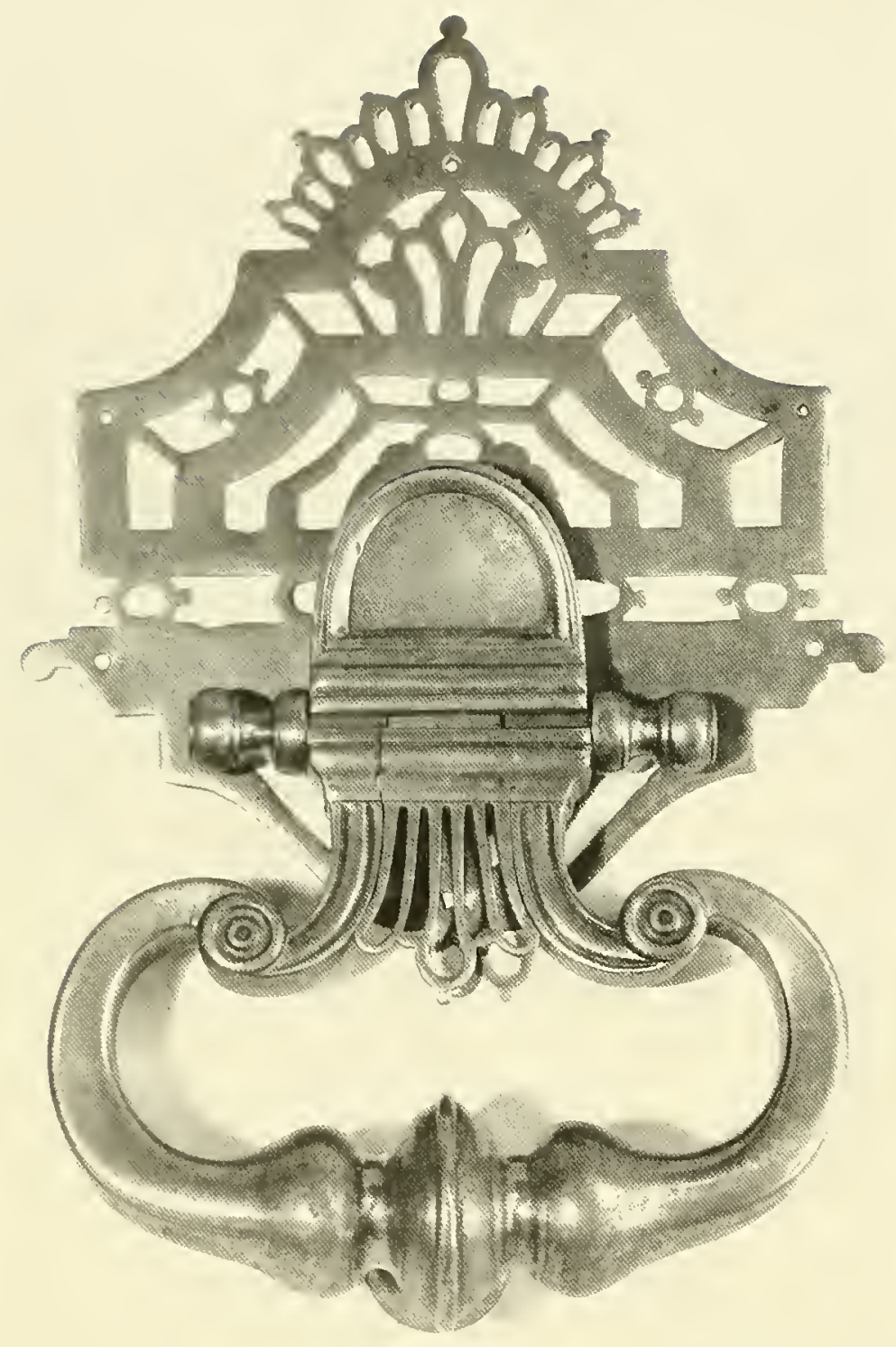

The adormment of doors is an old art, at times brought to perilous perfection, as when the forger of the ornamental hinges on the doors of NotreDane-de-Paris was accused of having resorted to the help of the Devil in making the finely wrought scrollwork. In a more enlightened age, the master forger who shaped this door knocker for a patrician house in Bordeaur probably escaped similar charges. The heavy Baroque handle contrasts pleasingly with the openwork plate, into which it is set and which suggests its date as the second lialf of the 18th century. A gift of John kenneth Krug, this door knocker forms an interesting addition to the Mluseum's varied collection of ornamental ironwork. H.B.

Height, $12 \frac{1}{2}$ in. $\quad\left[1957^{-161-1}\right]$ 
Exclange of goods with other countries and continents has constantly contributed to the enriclument of Western Man's surroundings. As contacts with the Orient expanded in the 1 -th and 18 th centuries, Europe learned to profit from the artistic traditions of the East as well as from its manual skills. Chinese painters produced wallpaper for the Western trade, porcelain decorators painted armorial bearings of aristocrats unknown to them on thousands of plates and dishes, and furniture makers followed drawings sent them through the East India Company. This early 19th-century bamboo chair, a gift of Mrs. Willian Pedlar, was made in China for the English market, in a styte which found its apogee in the Royal Pavilion at Brighton. It is a good example of how crosscurrents of taste and skills may lead the imagination on delightful trips to far-off lands. H.B.

$$
\text { Height, } 55^{1 / 4} \text { in. } \quad\left[19^{62-75^{-1}}\right]
$$

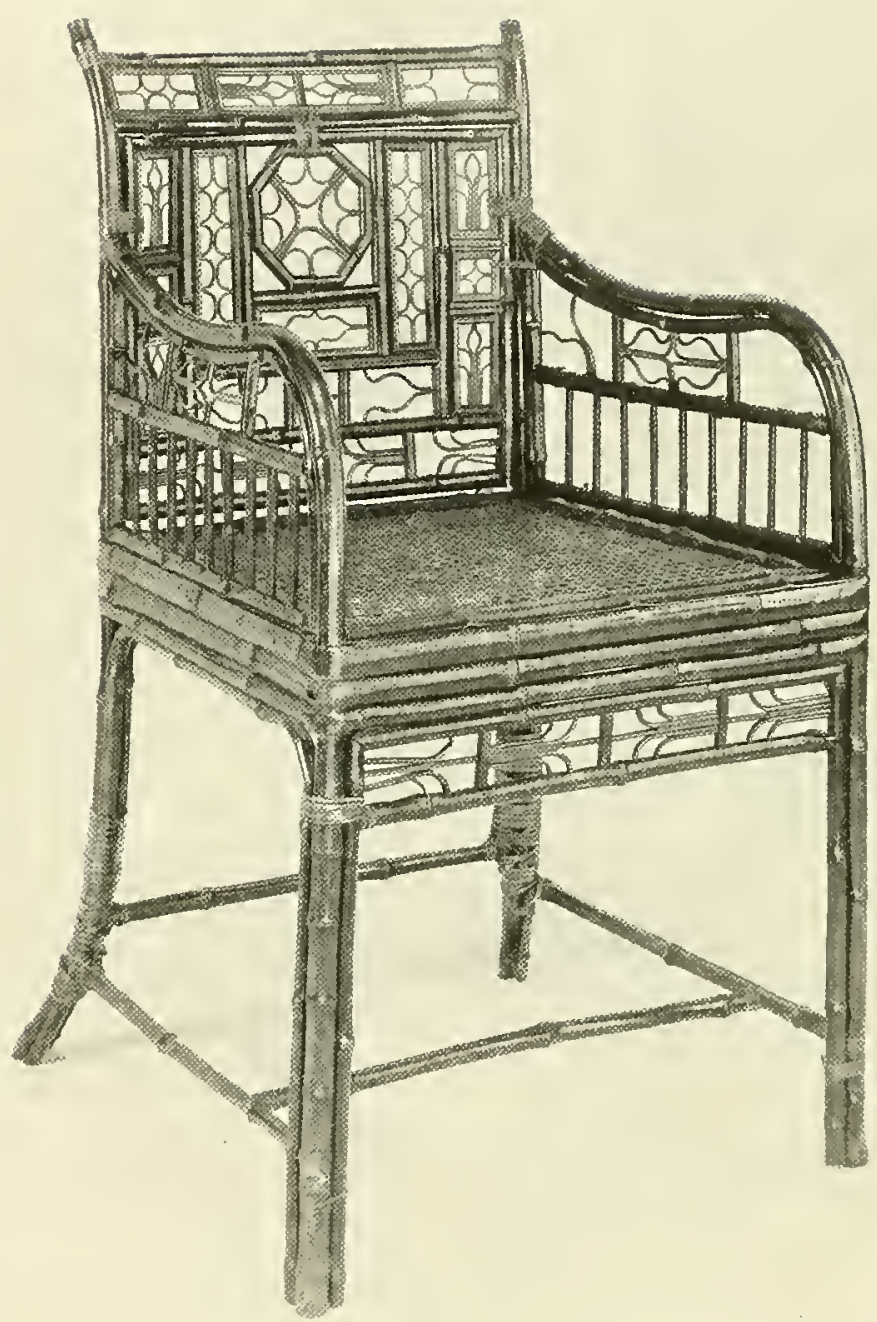




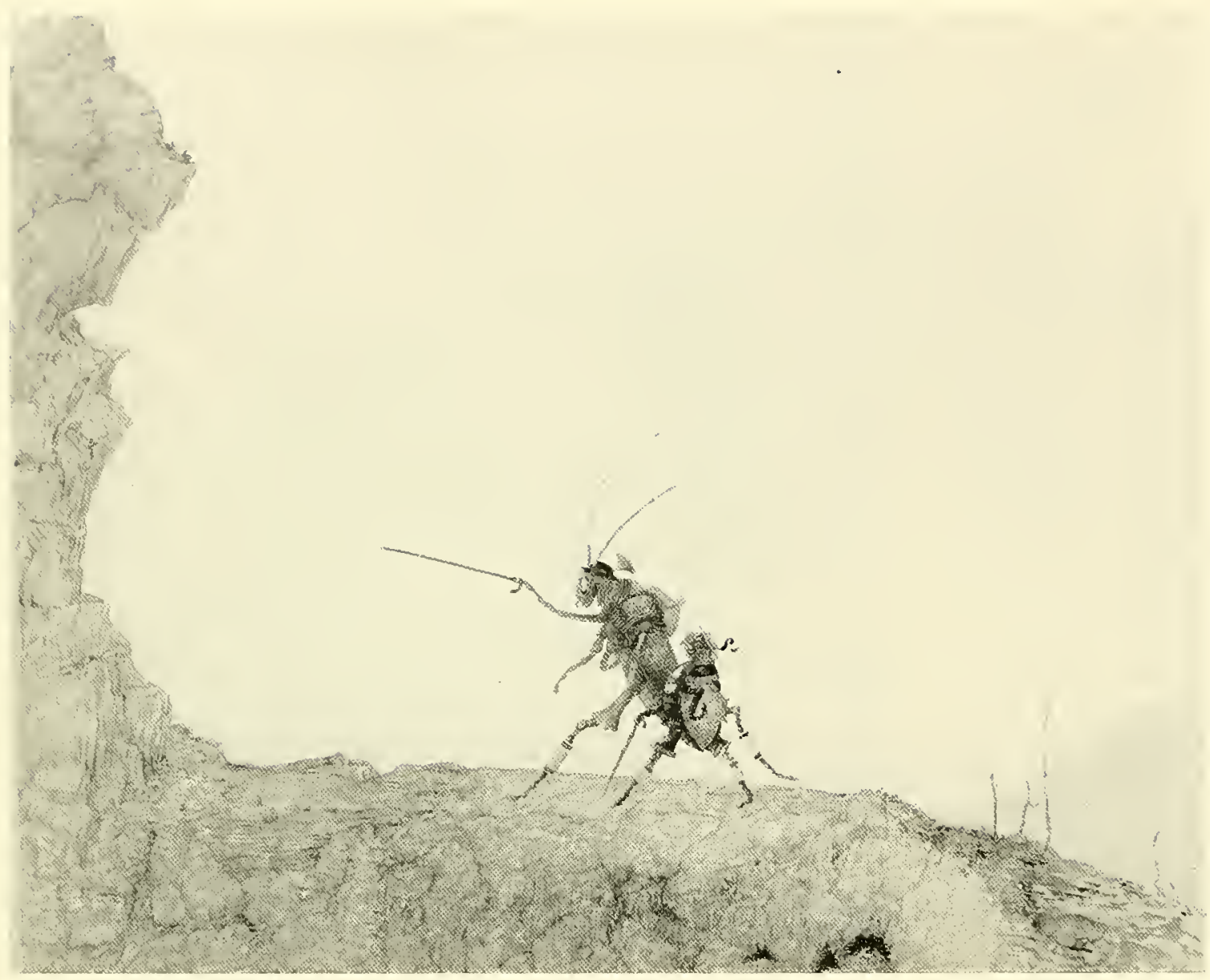

$81 / 4 \times 11$ in. $\quad[1961-89-1]$

A-Guinivg Mte Mre Go is the title of this charming drawing by the German-born artist, Baron Ermst von Maydell (1888-1961). It is a rather free interpretation of the well-known fable of La Fontaine, The Grasshopper and the Ant. Von Maydell's art is characterized by an extreme delicacy both of line and of color, his favored medium being a fine-pointed pen and ink with watercolors. This illustration, apparently never published in book form, one of two by this artist in the Museum's collection, was given by Alan L. Wolfe. R.P.W. 
In the silver and plique-á-jour candlestick by West-Coast craftsman Ruth Penington, brilliantly colored drops of translucent enamel are contained in the silver circlets within the novable roundels. A techmique which was cheapened by misuse in badly designed igth-century pieces, plique-ia-jour enameling was revived recently by contemporary craftsmen who combine mannal skill with creative design. The miniature stainerl glass effect of the difficult technique is used in this candlestick to particular advantage. H. B.

Hcight, 81/4 in. [1959-176-1]

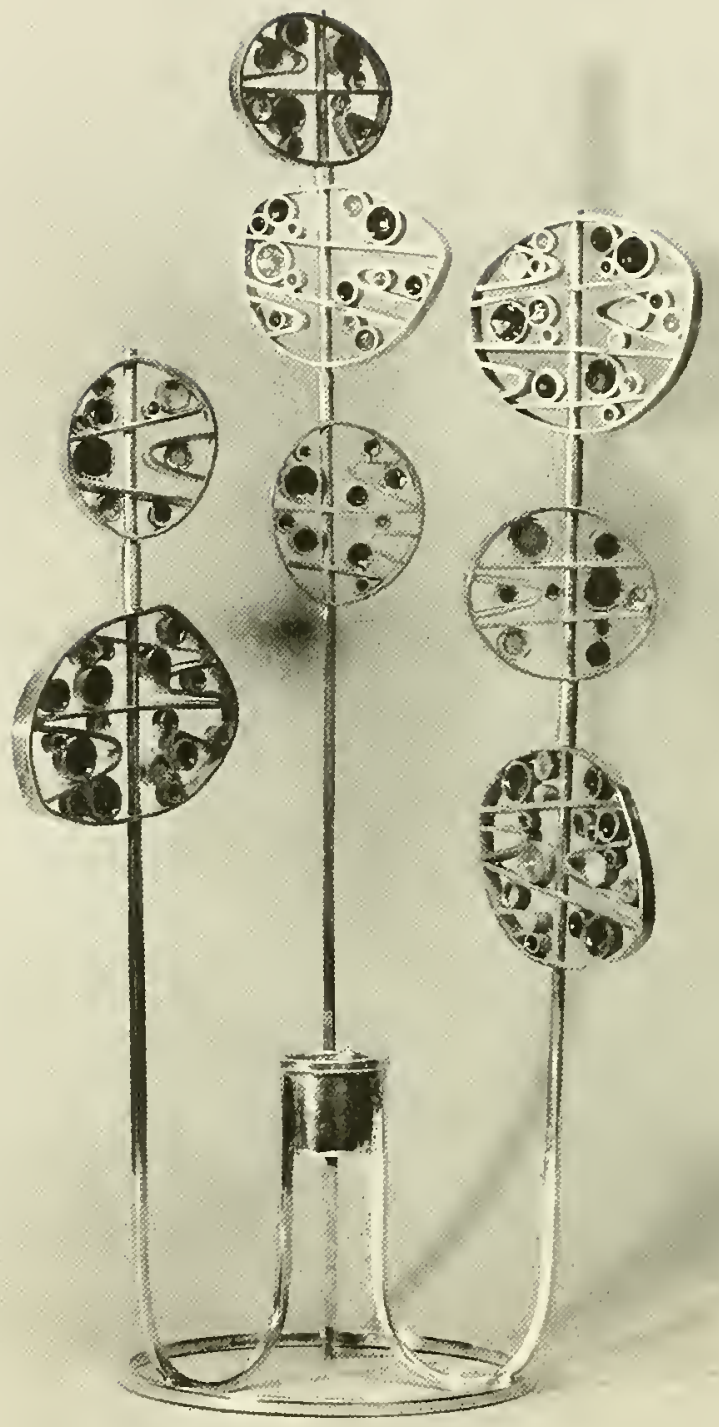




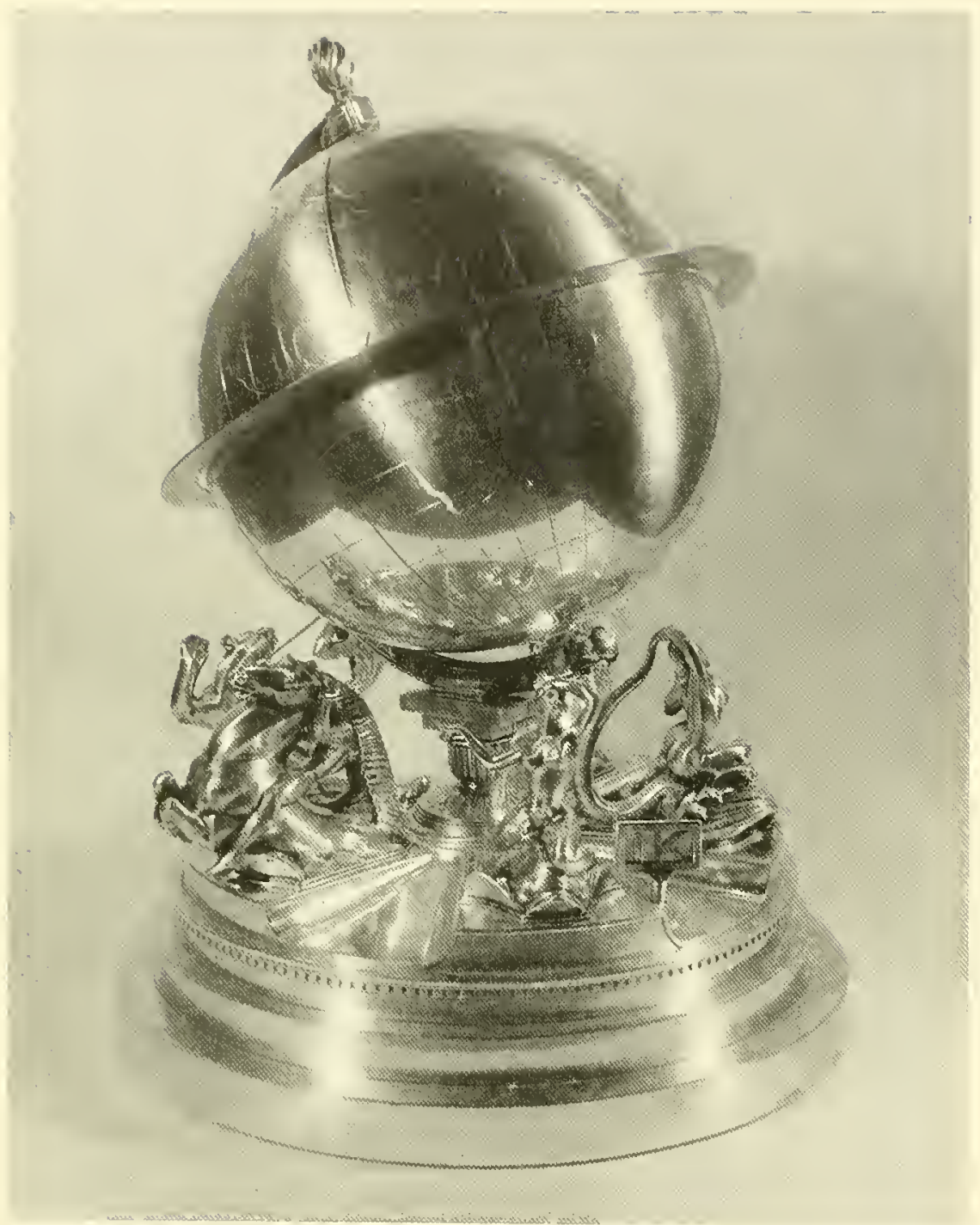

Height, $181 / 8$ in. $\quad[1960-1-16]$
It is not unusual to collect objects representing a certain subject in art, but such collecting can become monotonous if the theme does not offer the possibility of sufficient variation. In interesting himself in collecting art works representing the Four Continents, the late James I Iazen Hyde chose a subject of almost linitless possibilities. As an allegory in the manner of the Four Seasons, or the Four Temperaments, or as the apotheosis of Church or King, the Four Continents were subjects favored from the late Renaissance through the Baroque and Rococo periods. When Australia, or Oceania as it was also called, was recognized as a continental entity, the decorative schemes in which the Four Continents were used became rarer. But the old concept of world-wide homage to the powerful and mighty was revived in this terrestrial globe clock with its pedestal surrounded by five allegorical figures. The twenty-four hours of the day are inscribed on the equator, and the meridian of Stockholm, marked with an arrow, turns with the globe and marks the time. Made by the Court silversmith, Baron Erik Flenıing, it was a gift of the Swedish Match Company to its head, Irar Kreıger, on his fiftieth birthday in $195^{\circ}$. I1. B. 


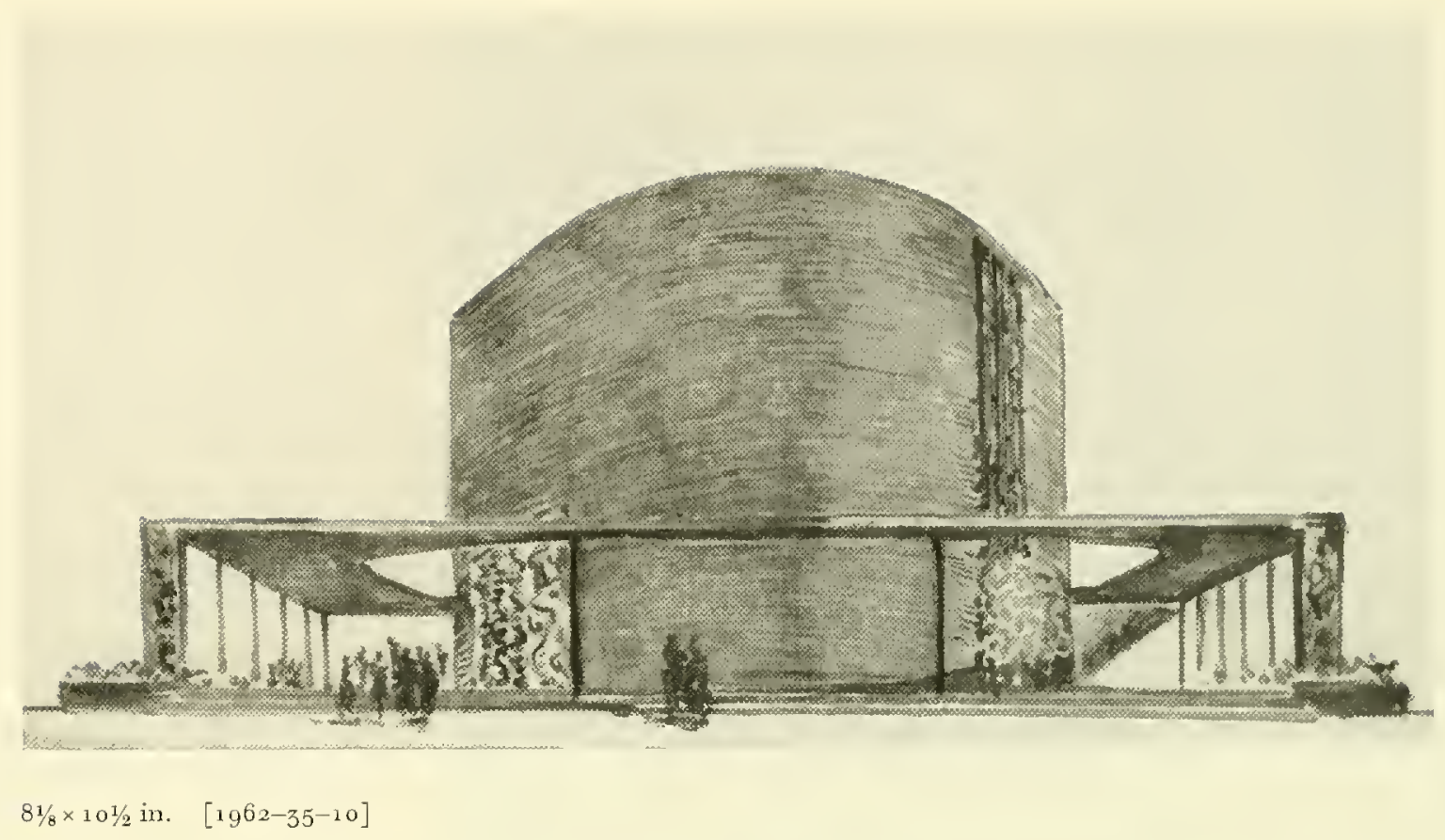

Teacher and theoretician, Pietro Belluschi is known above all as a church architect. The design problem here presented was to provide an appropriate edifice for the First Lutheran Church, locater on a busy intersection in Boston's residential Back Bay quarter. In this first, inaginary design of $195^{8}$, the architect lets the side courts provide a subtle transition from outdoors to indoors. As built, the church has proved to be excellently adapted both for music and for speech. Like masy conceptrual sketches by today's architects, this drawing, one of a group given the Museum by Mr. Belluschi, is carried out with a felt markingpen on tracing paper. R.P.W. 


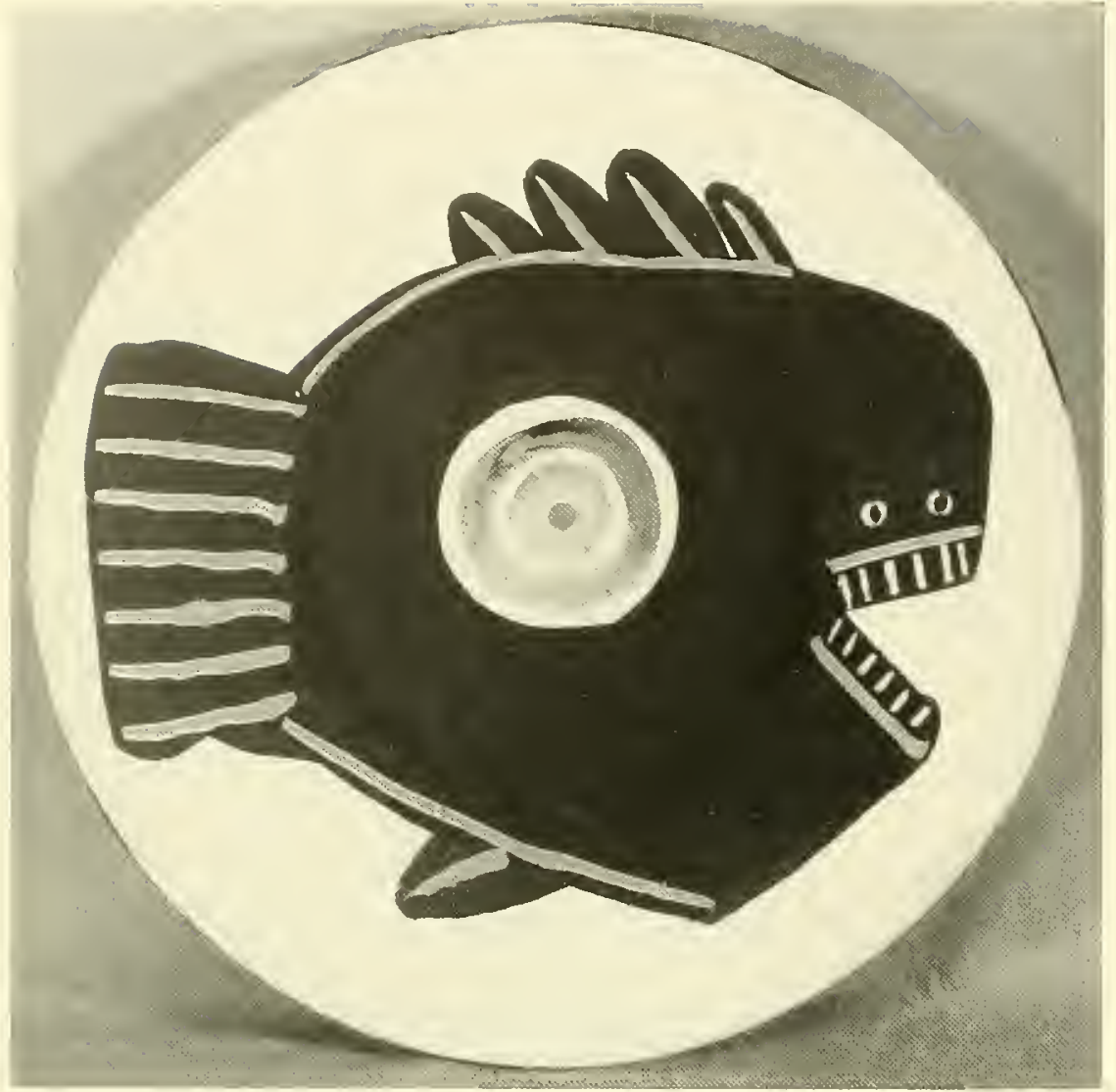

The appeal of clay is so basic and primitive, and its possibilities of decorative expression so varied, that artists accustomed to other media often succumb to its temptations. Pablo Picasso, fascinated by the work of the village potters in Vallauris, on the French Riviera, tried his hand also at potterymaking, and enjoyed the shaping of the wet clay as much as the decorating of the finished piece.
Dianeter, $17 \frac{1}{4}$ in. $\quad[1960-112-1]$

With the center of the large platter as the focus for the design, his Gros Porsson NOIR appears in a forceful and at the same time humorous exaggeration of its clumsy proportions. The platter, a gift of Mr. and Mrs. Daniel Saidenberg, carries on the back a series of painted and graffito faces, with the signature of the artist, and the date, April 16, $1957^{\circ}$ H. B. 


$$
12^{3 / 8} \times 125 / 8 \text { in. } \quad[1960-21+-65]
$$

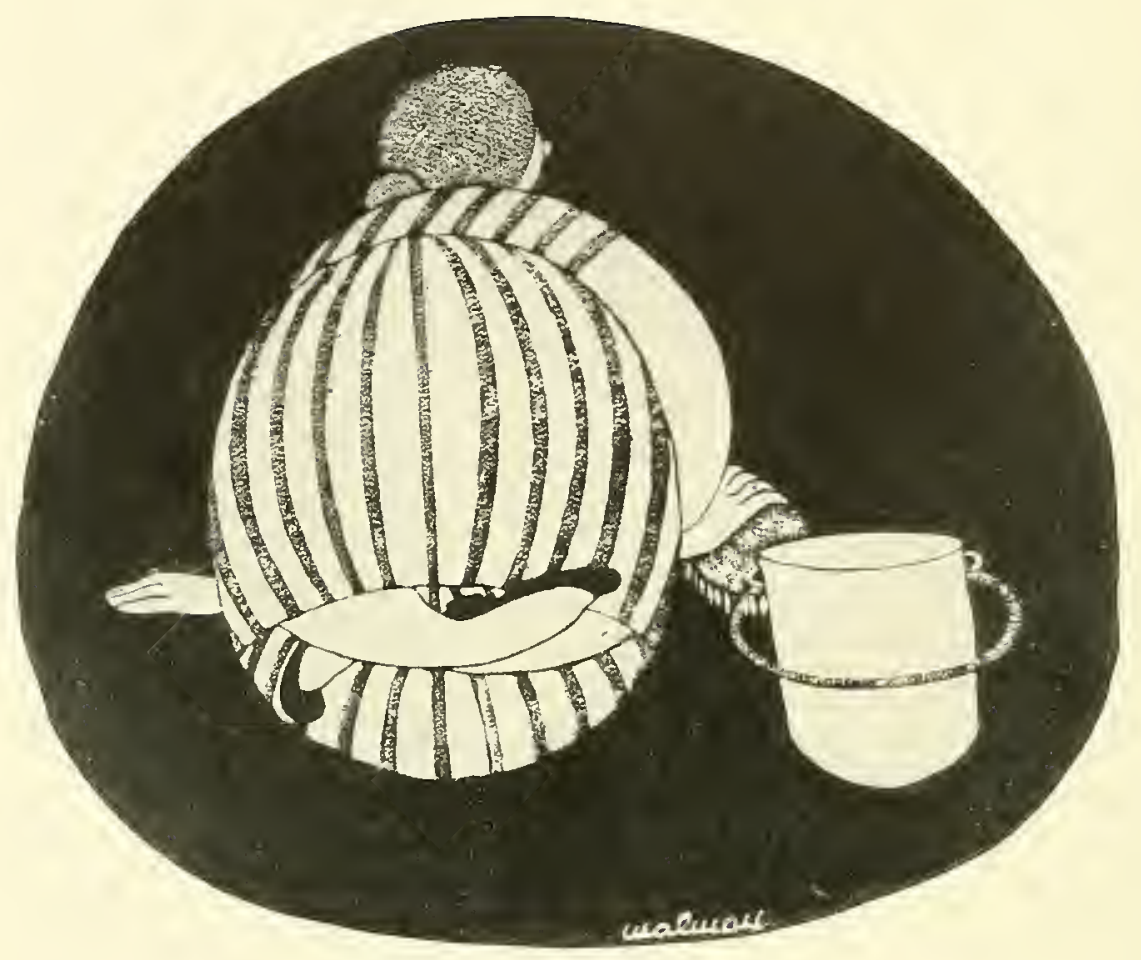

Readers of The New Yorker over the years are all familiar with the cartoons and "spots" by the late Christina Malman. Few magazine illustrators have possessed as keen a sense of design, originality in humor and subject matter, and inventiveness in technique. This lllustration for Fiction Parade, thongh dating about $193^{8}$, is actually timeless in its humor. The medium is pencil, brush, and india ink, with the highlights brought out by means of dry brush and white poster paint. This example belongs to a group of more than a hundred drawings in the Museum's collection by Miss Malman for illustrations and magazine covers, given by Dexter Masters. R.P.w. 


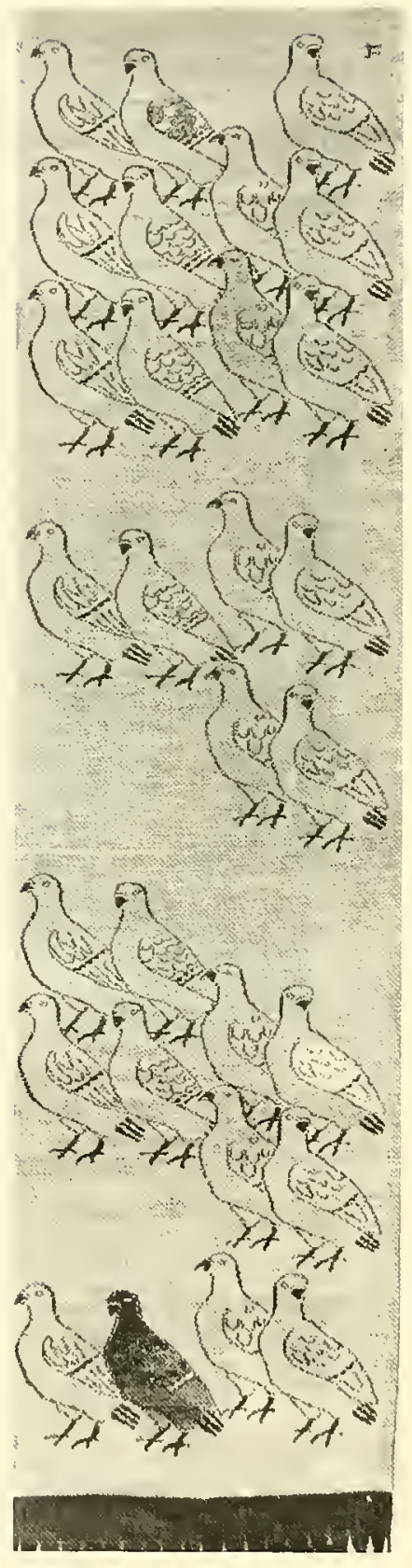

From what familiar forms a pattern of such satisfying quality may be derived is shown in the panel designed and woven about 194.8 by Dora Jung, of Finland. Here, the casual, ambling line of pigeons-commonest of city birds-is rendered in greys, white and occasional touches of red ancl gold color in a linen damask. The rhythmic and deceptively simple design results in a highly attractive wall hanging. A.B.B.

$81 \times 20$ in. $\quad\left[1959^{-1}+5^{-1}\right]$ 
Printed by Clarke d. Way, Inc., New York 

